\title{
For a General Theory of Health: preliminary epistemological and anthropological notes
}

\author{
Para uma Teoria Geral da Saúde: anotações \\ epistemológicas e antropológicas preliminares
}

Naomar de Almeida Filho 1

\footnotetext{
1 Instituto de Saúde Coletiva Universidade Federal da Bahia. Rua Padre Feijó 29, 4o andar, Salvador, BA 40110-170, Brasil.
}

\begin{abstract}
In order to conduct a preliminary evaluation of the conditions allowing for a General Theory of Health, theauthor explores two important structural dimensions of the scientific health field: the socio-anthropological dimension and the epistemological dimension. As a preliminary semantic framework, he adopts the foll owing definitions in English and Portuguese for two series of meanings: disease $=$ patologia, disorder $=$ transtorno, illness $=$ enfermidade, sickness $=$ doença, and malady =moléstia. Hebegins by discussing some sociological theories and biomedical concepts of health-disease, which, despite their limitations, can be used as a point of departure for this undertaking,gi ven the dialectical and multidimensional nature of the disease-illness-sickness complex (DIS). Second, he presents and evaluates some underlying soci o-anthropological theories of disease, taking advantage of the opportunity to highlight the semeiologic treatment of health-disease through the theory of "signs, meanings, and health practices". Third, he analyzes several epistemological issues relating to the Health theme, seeking to justify its status as a scientific object. Finally, the author focuses the discussion on a proposal to systematize various health concepts as an initial stage for the theoretical construction of the Collective Health field. Key words Epidemiologic Models;Theoretical Models; Epidemiologic Methods
\end{abstract}

Resumo Com o objetivo de avaliar preliminarmente as condições de possibilidade de uma Teoria Geral da Saúde, explora-se duas das mais i mportantes di mensões estruturantes do campo científico da saúde: a dimensão sócio-antropológi ca e a dimensão epistemológica. Como marcação semântica prel iminar, propõe-se uma fixação de senti do em Português para duas séries significantes: disease $=$ patologia, disorder $=$ transtorno, illness $=$ enfermidade, sickness $=$ doença, malady =moléstia. Inicial mente, discute-se al gu mas teori as sociol ógicas e concepções bi omédicas de saú de- doença que, não obstantesuas limitações, sem dúvi da poderão ser tomadas como ponto de parti da para este esforço, dado o caráter dialético e multidimensi onal do Compl exo D-E-P (doença-enfermi dade-patol ogia). Em segundo lugar, al gumas abordagens sócioantropológi cas articuladoras de teorias de doença são apresentadas e aval iadas, aprovei tandose a oportunidade para destacar um tratamento semi ológi co da saúde-doença, através da teoria dos "si gnos, si gnificados e práticas de saú de". Em tercei ro lugar, anali sam-se al gumas questões epistemológi cas em torno do tema Saúde, buscando justificar o seu estatuto de objeto científico. Finalmente, col oca-se em di scussão uma proposta de sistematização de di stintos conceitos de saúde, como etapa inicial para a construção teórica do campo da SaúdeColetiva.

Palavras-chave Modelos Epidemiológicos; Modelos Teóricos; Métodos Epidemiológicos 


\section{Introduction}

In the various disciplines comprising the socalled heal th field, we observe timid attempts at conceptually constructing the "health" object (Czeresnia, 1999: Levine, 1995), in contrast with the extensive efforts at developing biomedical disease models (Abed, 1993; Berlinguer, 1988; Murphy, 1965; Pérez-Tamayo, 1988; Temkin, 1963), emphasizing the individual and sub-individual levels of analysis.

In order to conduct a preliminary assessment of the conditions allowing for a General Theory of Health, I propose herewith to explore two important underlying dimensions in the scientific field of health: the socio-anthropological dimension and the epistemological dimension. The epidemiological dimension of the health concept was the object of a specific paper (Almeida Filho, in press). Despite recognizing its importance and founding role, the biological dimension will not be covered here, except insofar as it proves indispensable to clarify some specific issue in the health-disease models analyzed herein. Aspects pertaining to the etymology of the term "health" were the object of a related article (Almeida Filho, 2000).

First, I intend to discuss some sociological theories of disease-illness-sickness and biomedical concepts of health, which, despite the limitations discussed below, can doubtless be taken as the point of departure for this undertaking, given the dialectical and multidimensional nature of the health-disease dyad. Second, I will present and assess several underlying socio-anthropological ap proaches to theories of disease, taking advantage of the opportunity to highlight the semeiologic treatment of health-disease through the theory of "signs, meanings, and health practices". Third, I will analyze several epistemological issues pertaining to the health theme, seeking to justify its status as a scientific object. Finally, I intend to focus the discussion on a proposal to systematize various concepts of heal th as the initial stage for their application to the theoretical construction of the Collective Health field.

Before entering into the discussion, I should provide a preliminary semantic framework. The Engl ish language, the matrix for this specific literature, makes subtle distinctions in meaning between the various concepts of disease and related terms, through two semantic series: disease-disorder-illness-sickness-malady and impairment-disability-handicap. These two series refer to a particular technical glossary, which due to its growing importance in contemporary scientific discourse deserves some attention in the sense of establishing a terminological equivalence in Portuguese, as indispensable background for participation by Brazilian researchers in this debate. Thus, even while recognizing that such attempts can be arbitrary and incomplete, I propose to adopt the following terminology, which I will adhere to strictly throughout the rest of this paper:

- disease = patologia,

- disorder =transtorno,

- illness =enfermidade,

- sickness =doença,

- malady =moléstia.

The irony of social theories of health

In the field of social sciences applied to health, since World War II there has been a somewhat insistent search to objectively define the concept of disease and its correlates (Humber \& Almeder, 1997), with a view towards formulating "social theories of health". This section reviews some of these proposals, originating mainly from Anglo-Saxon Medical Sociology.

Talcott Parsons, whose work ascribes an especially central role to health phenomena for an understanding of the social system, defined illness as a "state of disturbance in the normal functioning of the total human individual including the organism as a biological system as much as its personal and social adjustment" (Parsons 1951:431). Parson's theory of the sick role is the first conceptual reference to a series of definitions of the sickness concept as a societal component of the disease-illness complex, as we will see further on. Curiously, Parsons does not highlight the term disease in his theo$r y$, rather using illness and disorder, even when it is necessary to refer to the objective pathological aspects of disease (Parsons, 1951, 1964, 1975).

The author later proposed to analyze Health as a social function, defining it as a "state of optimum capacity for the effective performance of (socially) valued tasks" (Parsons, 1964). Parsonian functionalist theory served as the theoretical matrix for approaching individual health as a social role, performance, functioning, activity, and capacity, among others, which were subsequently condensed in the concept of health as social well-being, a characteristic of contemporary "quality of life" rhetoric.

It is difficult to establish who was the first author to systematically postul ate a distinction between disease, illness, and sickness. To justify at least a semantic difference between the first two terms, an initial attempt was to rely on 
common sense. As entries in the traditional Oxford Dictionary (1968), disease means "a condition of the body, or of some part or organ of the body, in which its functions are disturbed or deranged" and illness is simply defined as a "quality or condition of being ill (in various senses)".

Field (1976) conceptualized disease as an abnormality or pathological alteration recognized by means of a set of signs and symptoms defined on the basis of a biomedical conception. On the other hand, illness referred primarily to the subjective experience of an individual's state of "ill health", indicated by feelings of pain, discomfort, and malaise. Paying tribute to the Parsonian theory of the sick role, but without using the term sickness, Field (1976) further contended that illness did not simply imply a "biologically altered state", but also to be in a socially altered state which is seen as both deviant and (normally) undesirable.

In his seminal work Causal Thinking in the Health Sciences, Mervyn Susser (1973) presented two series of definitions that contributed little to overcoming the terminological confusion then prevailing, probably because of the limited diffusion of his writings outside of the epidemiological field. According to Susser, theterm disease refers to a pathophysiological process that causes a state of physiological or psychological dysfunction in the individual. On the other hand, illness is an individual, subjective state, a certain psychological and corporal awareness of the disease, while sickness implies a state of social dysfunction in the sick subject, corresponding to Parsons' sick role.

Philosopher Christopher Boorse (1975, 1977) defined disease as an internal state of the body resulting from subnormal functioning of some of its organs or sub-systems. Some such diseases can evolve to illness if they lead to limitations or disabilities that meet the following criteria: (i) that they be undesirable for the subject; (ii) that they be considered eligible for interventions; (iii) that they constitute a justification for normally reproachable social behaviors. Despite the clear functionalist inspiration (along the Durkheim-Parsons lineage), there is no special position in Boorse's original proposal for the term sickness, while illness constitutes a mere subset in the order of diseases, namely those that produce psychological and social consequences for the individual.

Boorse subsequently stated his intent (1977) "to offer a value free analysis" as the basis for a theoretical concept of Health, along the same lines as the biological concepts of life and death (amongst us Brazilians, the pioneer- ing work of Mário Chaves (1972) had already conceptualized health as an organism's capacity to function within an ecosystem resulting from the Eros-Thanatos opposition, in line of thought intriguingly similar to Boorse's proposal). Boorse proposed a linear articulation involving four basic concepts: "reference class", "normal function", “disease”, and "health". The reference class consists of the universe of members of a biological species of the same sex and age bracket. Normal function is defined as an individual contribution that is "statistically typical" in relation to the reference class for the species' survival and reproduction. Disease is a reduction in the "typical efficiency" involved in normal function. Health means simply the absence of disease. Boorse completes his "biostatistical theory of health" with an intentional tautology, indicating that health as a concept can simply imply normality, always "in the sense of the absence of disease conditions".

Contrary to the naturalist theoreticians (mainly Boorse) who believed in an objective and value-free approach to health-disease phenomena, Tristham Engelhardt (1975) identified a fallacy in this operation of considering abstract constructs as concrete things and preferred to treat them as differentiated and autonomous entities. Thus, he justified the definition of disease as a scientific category destined to explain and predict illness, suggesting that the latter, and not disease, was a referent for health phenomena. In his own words (Engelhardt, 1975:137): “Commitment to the concept of di sease presupposes that there are phenomena physical and mental which can be correlated with events of pain and suffering, so that their patterns can be explained, their courses predicted, and their outcomes influenced favorably".

Phenomenological approaches to health (Engelhardt, 1975) were critical of naturalist theories' objectivism. Recently, such criticism reached the extreme of challenging the usefulness of the very concept of disease (Hesslow, 1993), apparently with no echo among researchers involved in the important effort at theoretical construction of the field of Medical Sociology.

Seeking an alternative to the expanded use of the disease concept, which spawned confusion of both a logical and semantic order, some authors (Clouser et al., 1997; Culver \& Gert, 1982) proposed to adopt the more generic concept of malady. This concept supposedly denoted the universe of categories referring to damage or threats to individual health, including both the various classes of disease, illness, and sickness, as well as the events, states, and 
processes that were difficult to classify as sickness or disease, such as disorder, dysfunction, dependency, defect, lesion, trauma, etc. Despite the proposal's proper intentions, the concept of malady has not been incorporated into either the theoretical discourse of the Sociology of Health or the technical discourse of Clinical Medicine, and is mostly referred to as a curiosity indicating the insufficiency of the disease concept.

The Pörn-Nordenfeld theory (Pörn, 1984, 1993; Nordenfeld, 1987, 1993), developed as part of an effort at an economic and philosophical justification for Scandinavian "neowelfarism", was intended to recover a pragmatic definition of health based on updating and correcting Boorse's biostatistical approach. Despite the conceptual limitations and even a certain philosophical naiveté in this formulation, the proposal by Pörn (1984) is certainly interesting, i.e., that the symmetrical opposite of health is neither disease nor sickness, but rather illness (Pörn, 1984). In other words, health is not the objective absence of disease, but the nonexistence of illness in terms of adaptation of a human organism to a biological and social environment (Pörn, 1993).

Presenting a very well-structured theoretical formulation which he entitled the "phenomenology of health", Nordenfeld (1987) proposed a distinction between objective and subjective ill ness which, as a logical consequence of Pörn's health-illness continuum, leads to the mirror concept of "subjective health". Objective illness is defined by the potential functional capacity not affected by the cause of the disease, while objective health corresponds to the actual exercise of this functional capacity. According to this scheme, subjective illness (or nonheal th) has two components: (i) the awareness of illness (in the author's words, the "mere belief or awareness that someone is ill") and (ii) the feeling of illness (or the "set of mental states associated with illness"). Thus, as postulated by Nordenfeld, a person $\mathrm{P}$ is subjectively healthy if and only if he/ she (1) is not subjectively ill, (2) believes that he/ she is healthy, or (3) is not experiencing a mental state associated with some currently existing objective illness (Nordenfeld, 1987, 1993).

Along this same line, Fulford (1994) contends that not even the concept of disease is value-free, defending a pragmatic approach through the use of two different levels of analysis, one descriptive and the other interpretative. Given that the former level incorporates disease concepts in which a high degree of consensus prevails, according to Fulford it is nec- essary to focus more on the latter analytical level. In this case, disease concepts could be referred to generically as "failures". Disease would correspond to a "role failure", while illness would result from an "action failure". Finally, Fulford (1994) challenges the existence of a deterministic link between disease and illness, as postulated by the majority of the authors reviewed, indicating that the actual illness experience cannot be explained by disease concepts, that rather it must be understood as phenomenologically given.

Recently, Boorse (1997) self-critically admitted the need to overcome his negative-evolutive concept of health (based on the dysfunction-disease-illness gradient), proposing to replace it with the notion of "degrees of health". This entails an extremely narrow definition of positive heal th as the maximum possible degree of health as opposed to any reduction in optimum normal function for the reference class. According to this concept, normality has three levels of specification: theoretically normal, diagnostically normal, and therapeuticalIy normal. The logical opposite of the disease concept would be theoretical (or conceptual) normality. The respective antagonists would fit with the other levels of normality: diagnostically abnormal and therapeutically abnormal. Finally, Boorse analyzes the extreme situations of "illness" (as opposed to "wellness") and deathlife. The underlying relationships of belonging and opposition in this interesting scheme are found in Figure 1. Curiously enough, the essential framework of this proposal had also already been laid out in the study by Mário Chaves (1972) quoted above.

A partial inventory is in order at this point. To begin, nearly all of the authors and schools reviewed thus far present proposals marked by a predominantly biological frame of reference. Therefore, they almost inevitably lead to theories not of Health, but of pathological processes and their correlates, in which Health is necessarily seen as the absence of sickness. Consequently, one observes an emphasis on the subindividual and individual levels, where pathological and experiential processes actually occur. This chain of logical omissions, entailing a reduced focus on the concept of sickness and the sick role impedes a collective conceptualization of Health (except, of course, as the sum of individual absences of disease). Here we find a flagrant irony: despite the promising Parsonian debut, Medical Sociology has not proven capable of constructing a social theory of health. 
Anthropological models

of disease-illness-sickness

This section expounds on the issue of healthdisease models from the interpretative perspective of contemporary Medical Anthropology, converging on a proposal integrating the concepts of disease, illness, and sickness.

Arthur Kleinman, Leon Eisenberg, and Byron Good (Kleinman et al., 1978), seeking to enrich the analysis of non-biological components of health-disease phenomena, systematized in 1978 a model that ascribed special theoretical importance to the notion of "sickness", emphasizing the social and cultural aspects that had paradoxically been overlooked by previous sociological approaches. (Curiously, Kleinman and his disciples omitted prior conceptual developments, even those occurring within the field of social sciences in health as discussed in the previous section). This proposal was based on the distinction between biological and cultural dimensions of sickness, corresponding to two categories: disease and illness. The model is shown schematically in Figure 2, highlighting the implicitly negative definition of health as the absence of sickness.

From this perspective, the pathological functioning of organs or physiological systems occurs regardless of its recognition or perception by the individual or social environment. Within a frame of reference that is quite congruent with Boorse's theory, according to Kleinman (Kleinman, 1980, 1986; Kleinman et al., 1978), disease refers to al terations or dysfunction in biological and/or psychological processes, as defined by the biomedical concept. On the other hand, the illness category incorporates individual experience and perception visà-vis both the problems deriving from the disease and social reaction towards illness. The concept of illness thus relates to processes of signifying sickness. In addition to their cultural aspects, meanings also touch on particular symbolic aspects forming the illness itself within the individual psychological sphere, as well as the meanings created by the patient while dealing with the disease process (Massé, 1995).

Subsequently, Kleinman $(1988,1992)$ partially reviewed his original objectivist position, contending that both disease and illness are social constructs. IIIness means the way sick individuals perceive, express, and deal with the process of becoming ill. Illness is thus prior to sickness, which is produced on the basis of a technical reconstruction of professional discourse in the physician-patient encounter, through communication around the culturally
Figure 1

Boorse's degrees of health model.

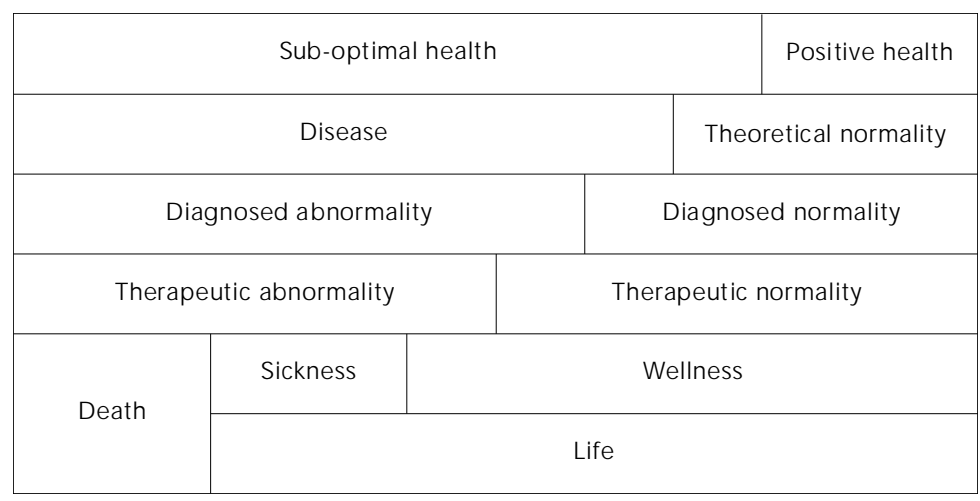

Figure 2

Kleinman \& Good model.

Sickness: disease + illness

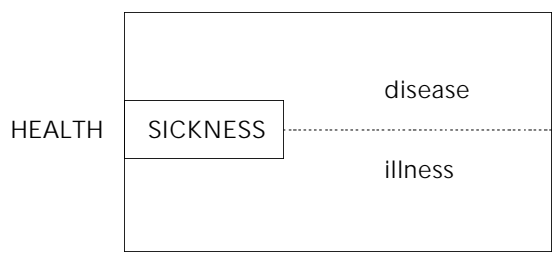

shared language of sickness. According to this same author (Kleinman, 1980), health, illness, and care are parts of a cultural system, and as such they should be understood through their mutual relations. To examine them separately distorts our understanding of both their respective characteristics and the way they function in a given context.

Kleinman (1986) further proposed that one of the reasons that different healing processes persist within the same society is because they act on different dimensions of sickness. Thus, one must consider different models capable of conceiving health and illness as resulting from the complex interaction among multiple factors at the biological, psychological, and sociological levels, with a terminology not limited to biomedicine. In order to construct such models, one must turn to new interdisciplinary 
methods, workingsimultaneously with ethnographic, clinical, epidemiological, historical, social, political, economic, technological, and psychological data.

Byron Good \& Mary-Jo Good (1980, 1982), reinforcing the perspective of intra- and intercultural relativism in illness, postulated that the borders between normal/pathological and health/ disease are established by illness experiences in different cultures, through the ways by which they are narrated, and by the rituals employed to reconstruct the world that suffering destroys. From this perspective, sickness (and by extension, health) is not a thing in itself, or even a representation of such a thing, but an object resulting from this interaction, capable of synthesizing multiple meanings.

Good \& Good (1980) proposed a "cultural hermeneutic model" to understand Western medical rationality. According to these authors, the interpretation of symptoms as a manifestation of the underlying "biological reality" is characteristic of clinical reasoning, since the latter is based epistemologically on an empiricist theory of language (Good \& Good, 1980). According to the biomedical health-disease model, clinical practice is supported by knowledge of causal chains operating at the biological level, following a script for decoding the patient's complaints in order to identify the underlying somatic or psychological pathological process. Thus, the model has a double objective: to establish the disease diagnosis and to propose effective and rational treatment. According to Good \& Good (1982), ascribing "symptom meaning" to an altered physiological state proves insufficient as a basis for clinical practice, since psychological, social, and cultural factors influence the experience of sickness, its manifestation, and the expression of symptoms.

One of the central points in this "critical reform" process in medical knowledge consists of the distinction between disease and ill ness. Agreeing with Kleinman, Good \& Good (1982) reaffirm that the disease process correlates with or is caused by biological and/or psychological alterations, while illness is situated in the domain of language and meaning and therefore constitutes a human experience. According to these authors, illness is fundamentally semantic, and the transformation of disease into a human experience and an object of medical attention occurs through a process of attribution of meaning. Thus, not only illness but also disease constitute a cultural construct, in this case based on theory and webs of significance comprising the different medical sub-cultures.
Meaning is not the product of a closed relationship between signifier and the thing (in the sense of an objective reality in the physical universe), but of a network of symbols constructed in the interpretative act, which they refer to as a "semantic network" (Good \& Good, 1982). IIIness becomes an experience with meaning for each particular individual. Even so, it is important to consider the relationship between individual meanings and the network of meanings inherent to each broader cultural context to which individuals belong. Therein lies the notion of illness as a "network of significance", in the sense of a reality constructed through a process of interpretation/signification, based on the plot of meanings that structures the culture itself and its various sub-cultures. Symptoms, full of at least individual meanings, allow access to biomedicine's web of significance, that is, culturally established disease signs in the form of a "syndrome of meanings" (Good \& Good, 1980).

In an attempt to develop an approach to the determination of sickness in societies based on analysis of social relations of production, Allan Young $(1980,1982)$ presents a critique of sickness models as proposed by Kleinman and Good \& Good. On the one hand, he postulates that the Kleinman-Good model only sees the individual as object and arena for significant events regarding illness, failing to report the ways by which social relations form and distribute it. On the other hand, while acknowledging the Kleinman-Good model's advances over the biomedical model, Young contends that the distinction between disease and illness is insufficient to explain the social dimensions of the process of becoming ill.

To overcome these limitations, Young (1980) proposes to replace the Kleinman-Good scheme [sickness $=$ disease + illness] with a triple series of categories (sickness, illness, and disease) with equivalent hierarchical levels, al beit granting greater theoretical relevance to the "sickness" component. It is in this sense that Young ends up postulating an "anthropology of sickness" (Young, 1982). Herein, I propose to designate the Young model as DIS Complex (diseaseillness-sickness), as represented in Figure 3.

According to Young (1982), although Kleinman emphasizes the social determinants of the explanatory models and Good highlights the power relations in medical discourses and practices, neither actually undertakes an analysis of these aspects in their work. According to Young, medical practices display an important political and ideological component, based on power relations that justify unequal distribution of 
illness and treatments, as well as their consequences. Therefore, the elements of the DIS Complex (disease-illness-sickness) complex are not neutral terms, but rather entail a circular process by which biological and behavioral signs are socially signified as symptoms. These symptoms, in turn, are interpreted by way of a semeiology that associates them with certain etiologies and that justify interventions whose results end up legitimating them as diagnostic signs of certain diseases. The author further comments that in pluralistic medical systems, a set of signs can designate different illnesses and therapeutic practices that fail to overlap. Social forces are what determine which individuals suffer certain illnesses, display certain sicknesses, and have access to given treatments. Depending on the sick individual's socioeconomic position, the same disease can imply different illnesses and sicknesses and different healing processes.

According to Young (1980, 1982), the concept of sickness should incorporate the process of ascribing socially acknowledged meanings to signs of deviant behaviors and biological signals, transforming them into socially si gnificant symptoms and events. In his own words, "Si ckness is a process for socializing di sease and illness" (Young, 1982:270). This process of socializing disease - or better still, of social construction of sickness - occurs in part within and through medical systems, linked to society's broader ideological circuits. Young states that this ideological dimension, through different forms of health knowledge and practice, reproduces specific views of the social order and acts to maintain them. In the final analysis, representations of sickness constitute elements in the mystification of its social origin and social conditions in the production of knowledge. According to Young (1980), the translation of forms of suffering (illness) derived from class relations in medical terms constitutes a neutralization process following the interests of the hegemonic classes. That is, through the medicalization process, the ill condition is reduced to the individual biological level, failing to consider its social, political, and historical dimensions.

Indeed, the focus on sickness supplants the emphasis on the individual or micro-social levels (characteristic of Kleinman's approach, for example). However, although it is an important step forward over its predecessors, Young's DIS Complex opens only one possibility for incorporating the Health issue: once again the mere absence of disease-illness-sickness.

In conclusion, one should value the effort at drafting a general theory of health-disease-
Figure 3

Young model.

DIS Complex

(Disease-IIIness-Sickness)

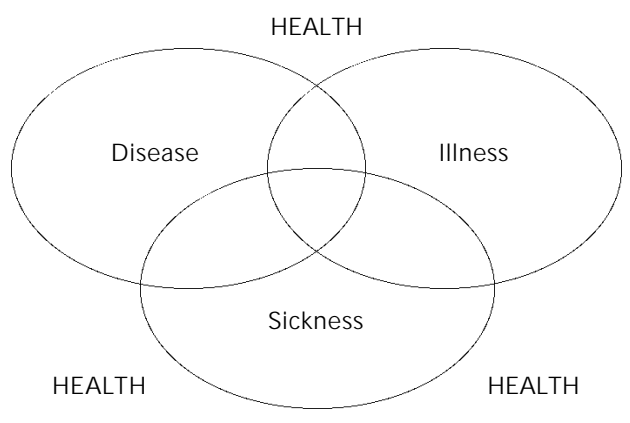

care, a badge of the intellectual undertaking of these distinguished heirs to the applied anthropology of the 1970s. Even considering the importance ascribed to patients' beliefs and cultural and personal meanings, as well as the proposal for integrating various components of health care systems and their respective explanatory models, the view of these theoreticians towards the conceptual issue of Health is not sufficiently transdisciplinary to broaden the scope of the medical anthropological approach, restricted to the view of Health as absence of illness. The Kleinman-Good and Young models actually remain constrained to curative practices, focusing on the ill individual's return to normal functioning and healthy life, without even entering into the definition of normality or actually analyzing if the Health concept fits into it.

\section{Semeiologic approaches \\ to health-disease-care}

Recently, Good (1994) developed a critical semeiologic perspective for the analysis of healthdisease models, reevaluating the semantic network concept, identifying two limitations to it:

The first relates to the redefinition of the DIS Complex in light of linguistic theory, given the insufficiency of the perspective according to which a symbol condenses multiple meanings. According to Good, one must recognize the diversity of national, ethnic, religious, and professional languages in the contemporary world, as well as the multiplicity of voices, the 
individuality of these voices, in short, an interdialogue and an alter-dialogue present in the construction of discourses on health-disease. IIIness is not only constituted by the individual point of view, but by multiple and frequently conflicting pathways; in this sense it is dialogic. Even while illness is synthesized in familiar narratives, loaded with gender and kinship policies, it is also (and now as disease) objectified as a specific form of physiological disorder in case presentations and conversations among physicians, even if these objectification can be subverted or resisted by patients. Sickness is immersed in a social web in which everyone negotiates the constitution of the medical object and the guidance of the material body.

The second limitation to the analysis of semantic networks refers to the reduced possibility of representing the diversity of forms of authority and resistance associated with the medical system's central elements. Semantic networks, albeit produced by power and authority structures, can provide the necessary means to understand how hegemonic forms are organized and reproduced, since they are culturally rooted and sustain discourses and practices. However, Good (1994) acknowledges that this relationship between semantic structures and hegemonic power relations has not been sufficiently developed by the main authors in this theoretical field, as maintained by Young's radical critique.

The notion of semantic network should thus be expanded to indicate that the meaning of sickness is not univocal, but the product of interconnections. It is no longer just a syndrome of meanings, but also a syndrome of experiences, words, feelings, and actions involving different members of society. This set of elements is condensed in the essential symbols of the medical lexicon, implying that such diversity can be culturally synthesized and objectified. Semantic networks constitute deep structures that link illness to a culture's fundamental values, meanwhile remaining outside of the explicit cultural knowledge and awareness of the society's members, presenting themselves as natural. This new analytical agenda for semantic networks (Good, 1994) treats the DIS Complex as a narrative, both natural and cultural, resulting from concrete, partially indeterminate sickness processes, a veritable script marked by a plot with different perspectives.

Advancing such critical perspective, Gilles Bibeau and Ellen Corin state that contemporary cultural anthropology, through its interpretative and phenomenological watersheds, has proven incapable of dealing with the com- plexity of health and sickness processes. This necessarily results from the emphasis on the study of subjective experiences in falling ill and the reification of sickness narratives, taken as autonomous texts, without ever establishing relations with ei ther the overall sociocultural context or the disease's "objective" dimension. Despite emphasizing the importance of cultural values and the influence of the semantic network concept in their work, Bibeau, Corin, and collaborators (Almeida Filho et al., unpublished manuscript; Bibeau, 1988, 1994; Bibeau \& Corin, 1994, 1995; Corin, 1995; Corin et al., 1993; Corin \& Lauzon, 1992; INECOM, 1993) reaffirm the need for a macro-social and historical approach to understand local contexts. This means establishing an epistemological, theoretical, and methodological connection between different dimensions of reality, articulating a meta-synthetic theory or "global perspective" (Bibeau, 1988) intended to integrate essential semeiologic, interpretative, and pragmatic elements for a cultural model of healthdisease-care. In the particular sphere of health, the issue is to explore the relations between semeiologic systems of meanings and external conditions for production (the economic-political context and its historical determination) and the experience of fall ing ill (Corin, 1995).

Seeking to analyze the issue of different levels of determination in health phenomena, these authors (Bibeau, 1994; Bibeau \& Corin, 1994; Corin, 1995) propose an analytical scheme based on two central categories: collectivestructuring conditions and organizing experiences. Using these concepts, they intend to represent the different contextual (social and cultural) elements that link to form the systems of social responses towards "structural pathogenic devices". The structuring conditions encompass the macro-context, that is, environmental constraints, political power networks, economic development parameters, historical legacies, and daily conditions of existence (or modes of life). In other words, it is a matter of conditioning factors acting to modulate culture and limit functional freedom of action at the species and individual levels. Collective organizing experiences, in turn, represent the elements in the group's socio-symbolic universe that act to maintain the group's identity, value systems, and social organization (Bibeau, 1988). Thus, by postulating that semeiologic systems and modes of production link to produce the experience of falling ill, the authors retrieve Young's intent to consider the socioeconomic, political, and historical context in health-disease-care processes. 
From this perspective, Bibeau and Corin effectively point to an ouverture of meaning in the health field, implying a new view of the DIS Complex. They propose understanding the falling-ill process as based on the above-mentioned "global perspective", linking individual trajectories, cultural codes, the macro-social context, and historical determination. To this end, they advance an anthropological, semeiologic, and phenomenological theoretical framework to study local systems of signification and action vis-à-vis health problems. Such systems are rooted in the group's social dynamics and central cultural values underlying the individual construction of the falling-ill experience and collective construction of the social production of sickness (Bibeau, 1994; Bibeau \& Corin, 1994, 1995; Corin, 1995).

In the communities' spheres of symbolic production, corporal, linguistic, and behavioral signs are transformed into symptoms of a given illness, acquiring specific causal meanings and generating given social reactions, shaping what Bibeau \& Corin (Bibeau \& Corin, 1994) propose to call the "system of signs, meanings, and practices of health" (SmpH). In general, locally constructed popular knowledge is plural, fragmented, and even contradictory. Popular semeiology and cultural models of interpretation do not exist as an explicit body of knowledge, but are formed by a varied set of imaginary and symbolic elements, ritualized as rational. According to these authors, popular knowledge about $\mathrm{H}$ ealth and its counterparts (expressed in the DIS Complex) are linked and expressed in terms of socially and historically constructed $\mathrm{SmpH}$ systems.

SmpH systems thus shape a popular semeiology of health problems in context. To approach them systematically or "scientifically", the authors propose to look beyond the professional diagnostic criteria of the biomedical model and document the particular cases comprising actual cultural variations (Almeida Filho et al., unpublished manuscript; Bibeau \& Corin, 1994, 1995; Corin, 1995). In the daily process of defining categories and recognizing cases in these categories, "ordinary" people (the community, according to Bibeau \& Corin) do not necessarily function by identifying clear-cut categories of thought, but by perceiving similarities and analogies and establishing a continuity among cases according to a rich and fluctuating range of criteria (Almeida Filho et al., unpublished manuscript; Bibeau \& Corin, 1994, 1995; Corin, 1995). Component categories of SmpH systems are fragmented, contradictory, partially shared, locally constructed, orga- nized in multiple semantic and praxeological systems (i.e., structured in practices), in historical context, and accessible only through concrete situations - events, behaviors, and narratives. This mode of categorization refers to object-models formed by "Lakoff prototypes" instead of hierarchical classifications of discrete, mutually exclusive, and stable categories, typified by formally consistent logic. The concept of "prototype", key to linguist George Lakoff's theory (Lakoff, 1993), implies categories of fluid, imprecise meanings with relative degrees of stability, discriminated by fuzzy limits in definition. Because they differ from the categorical logic prevailing in Western, Aristotelian thinking, Lakoff prototypes can be better understood through alternative systems like Zadeh's fuzzy logic (as suggested by Lakoff himself) or Newton da Costa's para-consistent logic (Costa, 1989).

The theory is still being constructed and is thus quite incomplete, full of gaps and inconsistencies. Contrary to the approaches discussed earlier, the SmpH theory unhesitatingly presents itself as the basis for a General Theory of Health. Nevertheless, even in an indirect and attenuated way, this theory is still centered on illness, justified as such by the observation that popular semeiology is also structured on the concept of sickness and its correlates. On the other hand, by considering the biological field underlying the DIS Complex only in a partial and fragmented way, the $\mathrm{SmpH}$ approach runs the risk of structuring itself abstractly as a kind of anti-naturalism, prioritizing social, cultural, and linguistic aspects of sickness over the material and objective elements of disease, captured by modern medical technology. Of course, taking medical knowledge and clinical practice as cultural constructs (which they actually are), and consequently as objects of anthropological inquiry, does not shift the material basis of health-disease-care processes and phenomena. This theory merely outlines a broad definition of "structural pathogenic devices" by developing an analysis of different operational levels in the SmpH systems restricted to localglobal and social micro-macro polarities, characteristic of contemporary anthropological debate. Any heuristically efficient treatment of the Health issue will certainly have to anchor it in more complex explanatory models and broader conceptual spectra: that of the molecular-subindividual-systemic-ecological in the biological dimension and of the individualgroup-societal-cultural in the historical dimension. 
The epistemology of Health

What has been discussed thus far appears to shape a certain chronicle of a concept's resistance. "Health" is certainly not a docile or submissive object of analysis. It has resisted more or less competent attempts at domestication by the sciences of both structure and interpretation. A critical inventory of this effort leads one to conclude that the social and anthropological scientific approach to the Health issue has reached its limits, proving incapable of dealing with the properties of the object-model it intends to construct. But is the quest for a General Theory of Health really feasible, taking the heal th concept as a given object-model? In short, can health be treated as a scientific concept? Or, does this undertaking entail an underlying philosophical problem or some essential epistemological obstacle? If it is possible to conceive of Health as a concept, how can epistemology contribute to the effort? This section is intended to evaluate this set of questions.

Without a doubt, the nature of Health constitutes a secular philosophical question, perhaps of the magnitude of Russell's paradox or Hume's problems. Descartes identified it and Kant later systematized it as a basic problem for philosophy (Canguilhem, 1990). Therefore let us call it Kant's Problem.

Among the contemporary philosophers who have focused on the Health issue, Georges Canguilhem deserves special attention. In his inaugural work Le Normal et le Patologique (1978), Canguilhem indicated that the medical definition of normality stems largely from physiology, founding a positivity that impedes vi ewing sickness as a new form of life. Therefore, disease could not be admitted as an objective datum, given that positivist scientific methods only have the ability to define varieties or differences, without any positive or negative vital value.

From this perspective, the normality-pathology and health-disease conceptual dyads are not symmetrical or equival ent, to the extent that normal and pathological do not constitute contrary or contradictory concepts. Pathological does not mean the absence of norms, but the presence of other vitally inferior norms, which prevent the individual from experiencing the same mode of life allowed to healthy individuals. Hence, for Canguilhem, pathological corresponds directly to the concept of sick, implying the vital opposite of healthy. Possibilities in the state of health are superior to normal capacities: health constitutes a certain capacity to overcome the crises determined by the forces of disease to install a new physiological order.

Representing a historiographic watershed in the Canguilhemian theory of the normalpathological tension, Michel Foucault (1963, 1976) sought to indicate how new standards of normality emerged in the sphere of general and psychiatric medicine. In the context of 18th-century cultural reconstruction, attempts were made to intervene in human individuals, their bodies, their minds, and not only in the physical environment, to thereby normalize it for production. To list the normal possibilities for human yields and capacities, as well as the parameters for normal social functioning, became the task of psychiatric medicine, psychology, and applied social sciences. From this perspective, the implicit concepts in Foucault's work reveal his adherence to a definition of health as an adaptive capacity (or submission) to disciplinary powers.

Subsequently, Canguilhem (1966) stated that normality as a life norm constitutes a broader category, encompassing healthy and pathological as distinct sub-categories. In this sense, both health and sickness are normal, to the extent that both imply a certain life norm, where health is a superior life norm and sickness is an inferior one. Health is no longer limited to the perspective of adaptation, no longer unrestricted obedience to the established model. It is more than this, to the extent that it can constitute itself precisely by non-obedience and transformation. According to the elder Canguilhem (1966, 1990), health as the perfect absence of sickness is situated in the field of disease. The threshold between health and sickness is singular, although influenced by forces that transcend the strictly individual, like the cultural, socioeconomic, and political grounds (Caponi, 1997). In the final analysis, the influence of these contexts occurs at the individual level. Nevertheless, this influence does not directly determine the result (health or sickness) of this interaction, to the extent that its effects are subordinated to normative processes of symbolization.

Canguilhem systematizes his reflections on health in a little-known lecture given at the University of Strasbourg in 1988 and published in a limited edition (Canguilhem, 1990). In this paper, after a brief etymological analysis, referring back to Hippocratic ideas, Canguilhem notes that over the course of history, health was treated as if it could not be grasped by reason and thus did not belong to the scientific field. He dwells particularly on the philosopher Kant, who, as we have seen, provided the basis 
to position health as an object outside of the field of knowledge, whereby it could never be a scientific concept, but rather a commonplace, popular notion, within everyone's reach.

The idea that health is something individual, private, unique, and subjective has recently been defended by the eminent philosopher Hans-Georg Gadamer, one of the main exponents of contemporary hermeneutics (Gadamer, 1996). According to Gadamer, the mystery of health lies in its elliptic, enigmatic character. Heal th does not present itself to individuals. It cannot be measured, because it entails an internal agreement and cannot be controlled by external forces. Gadamer goes so far as to say that the mystery of health is equivalent to the mystery of life. In his opinion, the distinction between health and illness cannot be clearly defined. The distinction is pragmatic, and can only be accessed by the person who feels ill and who, no longer capable of dealing with the demands of life and the fear of death, decides to visit the doctor. Gadamer's conclusion (Gadamer, 1996) is simple: due to its private, personal, radically subjective nature, health can never be reduced to an object of science.

Canguilhem (1990) would agree that health is a philosophical issue to the extent that it escapes the reach of instruments, protocols, and scientific equipment, since it is defined as free and unconditional. This "philosophical health" would cover, but not be confused with, individual, private, and subjective health. It is a phenomenon without a concept, emerging from the praxeological relationship in the physicianpatient encounter, validated exclusively by the sick subject and his/her physician. Clinical knowledge is attributed to the mission of applying a technology and practice of protecting this subjective, individual health. Yet philosophical health does not only incorporate individual health, but also its complement, recognizable as a public health (i.e., a health made public).

The philosopher's notion of public health, referring to ethical and metaphysical questions (which would result for example in the notions of utility, quality of life, and happiness), moves away from the public health expert's concept of health, which understands the state of health of populations and its determinants, both in the sense of a complement to the epidemiological concept of risk and as a reference to the broader concept of the radical need for health. The concept of radical need comes from the post-Marxist Hungarian philosopher Agnes Heller (1986), providing an especially interesting conceptual opening for a General Theory of Health endeavor, to the extent that it implies health as something positive, albeit in the partial sense of filling an essential lack or need in a subject (like resistance or resilience) or society (as a positive health situation) (Paim, 1996). This proposal was applied to the health field by Ricardo Bruno Gonçalves, according to whom "heal th needs could be conceptualized as what must beachieved for a being to continue to bea being" (Gonçalves, 1992:19) - I owe this observation to Jairnilson Paim (personal communication).

Canguilhem (1990) is against the exclusion of health as an object of the scientific field, anticipating a stance contrary to that of Gadamer. He contends that health is realized in the genotype, in the subject's life history, and in the individual's relationship to the environment; hence, the idea of a philosophical health would not preclude taking health as a scientific object. While philosophical heal th would encompass individual health, scientific health would be public health, that is, a healthiness constituted in opposition to the idea of morbidity. Since the body is the product of complex processes of exchange with the environment, to the extent that these processes can contribute to determine the phenotype, health would correspond to an implied order both in the biological sphere of life and the mode of life (Canguilhem, 1990). As a product/ effect of a given mode of life, health implies a feeling of being able to confront the force of illness, thus functioning as a sort of openness towards social risks, as analyzed by Caponi (1997).

At this stage of his argument, Canguilhem refers to Hygiene, which begins as a traditional medical discipline, made of norms, not disguising its political ambition of regulating the lives of individuals. Beginning with Hygiene, health becomes an object of calculation and begins to lose its dimension as a private truth, receiving an empirical meaning as a set and effect of objective processes. Canguilhem (1990) insists that health is not only life in the silence of the organs, as affirmed by Leriche, but also life in the silence of social relations. It is from this perspective that we can insert the discourse of collective health as we know it. Yet Canguilhem (1990) contends after all that scientific health could also assimilate some aspects of individual, subjective, philosophical health, so that not only sickness and healthiness (or, using a more up-to-date terminology, the risks) should be studied by science. Figure 4 is an attempt at schematically depicting the Caguilhemian position on this issue.

It is curious to note that Canguilhem had already taken a stance on this question long 
Figure 4

Canguilhem model (adapted).

DIS Complex and Modes of Health

Philosophical health (value)

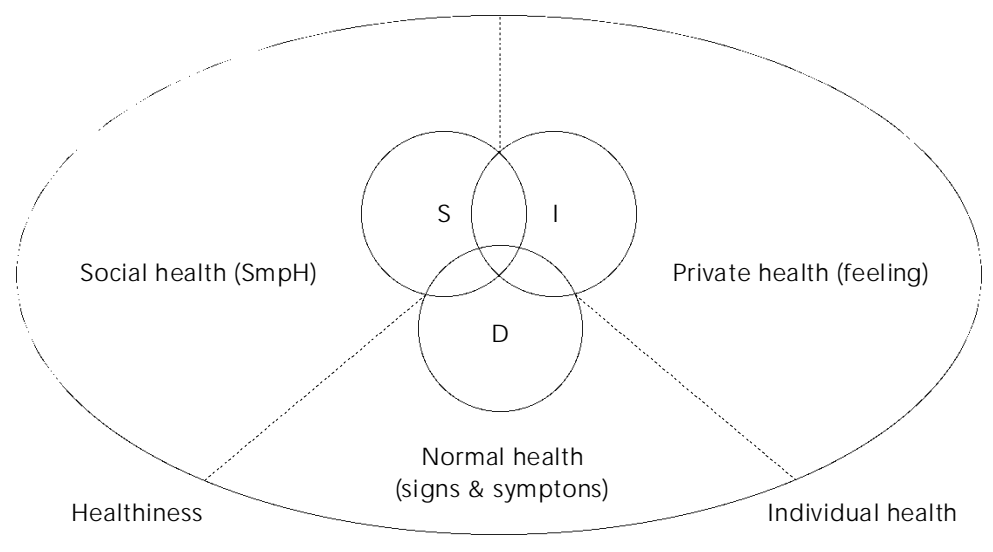

Scientific health (concept) before. On the one hand, he recognizes the health concept's potentially scientific quality, since even admitting that this does not refer to an existence, rather to a norm with function and value, "this does not mean that health is an empty concept" (Canguilhem, 1978:54). On the other hand, young Canguilhem finds no justification for a specific health science endeavor, at least at the individual level. In his own words: "If health islife in thesilence of the organs, there is no science of health per se. Health is organic innocence. And it must be lost, like all innocence, in order for knowledge to become possible" (Canguilhem, 1978:76)

In this same sense, the radically phenomenological Gadamerian perspective in defense of private, subjective, inherently enigmatic health would justify ruling out the feasibility of a scientific approach to health. However, I see as a paradox the fact that one of Gadamer's main proposals (Gadamer, 1996) turns out to be crucial for the advancement of an alternative formulation for the scientific object of heal th. Based on an etymological argument, as is his style, he defends the idea that health is inescapably all-encompassing, because its concept directly indicates wholeness or totality. From this angle, the Gadamerian notion of the "health enigma" ends up opening the way for a synthetic (or meta-synthetic, as we shall see later) approach to the scientific concept of health.

The Argentine epistemologist Juan Samaja, author of the classic Epistemología y Metodología (Samaja, 1994), a rare case of a philosopher with training and interest in Public Health, takes Canguilhem as his point of departure to investigate the conditions allowing for a scientific theory of health. Samaja (1997) criticizes both the Canguilhemian premise that the health concept is concerned fundamentally with the biological world and the implicit Foucaultian premise that proposes a purely social or merely discursive (ideological-political) concept of health.

According to Samaja (1997), the paradigm of Complex Adaptive Systems could serve as the epistemological basis for overcoming the biological-social antinomy, given conceptual demands al ready established by the development and practical use of the "health" notion in modern lay and technical discourses. In his opinion, one must conceive of the health concept as an object with distinct hierarchical facets, which "allows one to dialectically approach the health-disease dyad and the practices comprising it, leaving room for the recognition of various planes of emergence, in a complex system of adaptive processes" (Samaja, 1997:272).

Incorporating elements from contemporary critical hermeneutics, Samaja proposes that the object-model "health" should operate under four essential ontological determinations:

Normativeness. The heal th object is normative because it exists in and consists of the hierarchical interfaces in dynamic social and biological systems, both real and ideal, which shape the human world by means of processes involving the establishment and evaluation of norms for existence.

Dramaticism. The health object is dramatic in two senses: first, in the recursive sense, to the extent that it exists in and consists of iterative, reproductive, and transformative processes of the hierarchical interfaces; second, dramatic in a conflictive sense, given that each hierarchical order maintains a high level of autonomy and therefore of vulnerability vis-à-vis the interfaces.

Reflexivity. The health object is reflexive because it exists in and consists of the field of the professed senses and practices experienced through "productive-appropriative (specifically human) conduct".

Historicity. The health object has an ontosocio-genetic nature: it exists in and consists of the dialectic of structural processes that recapitulate past geneses. 
In this pathway of construction, which purposely takes health as a social value (and almost as an ideal type), Samaja highlights its complex, plural nature, fundamentally one of linking multiple determinations:

The object of Health Sciences, as a complex object that contains sub-objects with different levels of integration (cells, tissues, organisms; persons; families; neighborhoods; organizations; cities; nations...), entails a large number of hierarchical interfaces and an enormous amount of information, in which its experiences and postulations (both true and false) on normal/pathological, healthy/ill, and curative/ preventive acquire meanings and dramatic dimension (Samaja, 1997).

The author derives from these reflections a series of epistemological conclusions, amongst which he highlights that the theoretical health fiel d emerges from the production and formulation of what he calls a "politomorphous" knowledge on the normal-pathological dialectic. To this end, the interdisciplinary field of the health sciences is structured on the cognitive production of the various subordinate objects, revealing different planes of emergence and hierarchical interfaces. The fundamental question in this epistemological investigation consists precisely of the identification of the structuring interfaces in the multifaceted totality of the object-model "health". According to Samaja (1997), the main interfaces of Health are: "molecule//cell (specific category:autopoiesis); cell//organism (category: ontogenesis); organism//society (category: structural coupling)". (Samaja does not refer to an important intermediate interface, albeit one that occurs at a subindividual level, involving organs and systems in the organism, and whose specific category might be differentiation. I owe this observation to LígiaVieira da Silva, by way of personal communication.) In addition, he proposes to consider the interfaces in the societal sphere, playing out as follows: biosociety// gentilic society; gentilic society//political society. In short, Samaja's contribution is a critical proposition vis-à-vis Canguilhem's thinking, yet one that intermediates it, allowing for its instrumentalization as a frame of reference for a General Theory of Health.

Turning to both the sciences of symbolic systems and those of organized biological systems, Samaja proposes a perspective which doubtless overcomes Kant's Problem and updates Canguilhem's theory concerning the new paradigmatic developments in contemporary science. After all, in Kant's time only physics, astronomy, and natural history were consid- ered science. It is not surprising that for the founding philosopher of modern epistemology, it appeared inadmissible to consider a radically subjective question (like Health, at least at the individual level) as a potential problem for science. We should not forget that scientific psychology and anthropology had still not been created, that social relations, the unconscious, and the symbolic contents of culture and history were still not scientific objects, and that the ethnographic method had not been developed. In addition, clinical practice today is not what it used to be (as for example in young Canguilhem's time). Biotechnology has invaded/trespassed molecules, tissues, organs, the human body. Diagnostic classifications, the genetic code, and the immune system have increasingly become the object of so-called information sciences. A word of caution is thus in order vis-à-vis the radical constructionism permeating any Canguilhem-like analysis, which by appearing to ignore the naturalness of disease, becomes a source of abstract reflection which fails to instrumentalize a consistent critique of the hegemonic medical model.

\section{Modeling health}

As discussed above, the biomedical conceptions of health and the sociocultural theories of health-disease present major limitations that reduce their value as a conceptual reference to deal with the multidimensionality of the DIS Complex (disease-illness-sickness). Functionalist medical sociology developed processual models for the social determination of illness that only tangentially allow one to infer heal th as the result of a daily process of constructing social responses. Neither has medical anthropology ever proposed to define a theoretical category called "health", focusing on the ethnographic specificities of the notion of sickness and its correlates. Despite their theoretical and methodological advances, both perspectives focus on curative practices, and insofar as necessary define health as the absence of illness or sickness.

The thinking originating from Canguilhem's work effectively constituted an epistemological foundation of the utmost importance for developing new theories of health in the field of Collective Heal th (Caponi, 1997). Nonetheless, the philosophical approaches to the concepts of normality and health, by emphasizing the individual and subindividual levels of analysis, ended up reducing the scope of their contributions. 
Despite such limitations and criticisms, all this effort represents an in estimable contribution to theoretical advancement in the health field. In the current essay, it was possible to briefly consider the accumulated heuristic potential in the interfaces between the social sciences and the health sciences, thus the identification of some objective conditions for the formulation of a proposal to systematize the conceptual problem of Health.

From the preliminary exploration of the epistemological foundations of the health issue, one can retrieve the following potentially useful elements for the current proposal:

a) In accordance with anthropology's multivocal approach in Bibeu and Corin's systemic interpretation of health, the plurality of discourses structured with a scientific basis should be contemplated in this process, shaping descriptors capable of ordering the possibilities for the concept's empirical reference.

b) Converging with Canguilhem's stance, selected forms of the "health" concept can legitimately constitute an ontology of health as a scientific object.

c) Respecting the impasse raised by Gadamer, yet retrieving his argument regarding the holistic nature of heal th, the objectmodel "health" should incorporate a metasynthetic component into its construction, respecting its integrity-totality.

d) Considering Samaja's contribution, a constructive approach to the scientific quality of "health" should contemplate the field's hierarchical interfaces, organizing the concept's explanatory structures as a heuristic objectmodel.

Based on the investigation into the health concept in different contemporary discourses, I identify the following background issues indicating theoretical problems that must be overcome:

How to conceptualize health through the planes of emergence of phenomena and processes that define it concretely? Is it possible to define health as a single cross-section, by means of a theory capable of transmigrating from the individual-singular to the collective-social levels?

How to absorb the intuitive notion of health as absence of sickness into a positive concept of health? And how to link this incorporation into the various planes of emergence of healthdisease?

How to move towards a positive concept of health, considering the concept's historicity and its applicability as an underlying notion in processes of transformation of a given health situation?
Considering the definitions of hierarchical interfaces and planes of emergence and integrating the contributions by applied social sciences, as reviewed above, I propose an effort at semantic and theoretical specification of what could be called Modes of Health, as shown in Table I. This organizes the terminology used for categories of non-health available to the various heal th sciences, in addition to distinguishing between the variations in the definitions of normality and health and their potential empirical descriptors.

Like any schematic representation, this one is an attempt at depiction which is necessarily partial and impoverished in comparison to the rich and complex underlying reality. The various modalities of health and the corresponding categories of non-health are organized according to hierarchical planes of emergence: subindividual (systemic//tissual//cellular// molecular), individual (clinical// private), collective (epidemiological// populational// social). What I propose here is a glossary of categories for non-health which in a sense incorporates and expands the preliminary semantic demarcation of disease - illness - sickness. Note that the category "disorder" (or transtorno in Portuguese) occupies a level equivalent to the definition of disease in the clinical sphere.

As in any scheme, I seek to indicate equivalent descriptors for the respective level and sphere. Thus, at the subindividual level, normality and pathology (in the original Canguilhemian sense) correspond to the descriptor "state". At the individual level, in the clinical sphere, normal health corresponds to disease (structural) and disorder (functional), having "signs \& symptoms" as descriptors.

At the subindividual and individual planes of emergence, at any level of complexity, the health object can be examined based on an explanatory approach with a determinant basis, producing highly structured causal metaphors. In this case the issue is to produce (or polish) some partial facets of the object-model Health: the biomolecular process in the normal systems or the sustained physiological process in healthy subjects as equivalent to the pathological processes as manifested in the "case", or the "case of illness". The constitution of the Clinical Medicine disciplinary field around this facet of the total health-disease object has been treated both in historical/ epistemological as well as praxeological terms (Almeida FiIho, 1997; Clavreul, 1978).

Private health, with Gadamerian phenomenology, and individual health, the object of an "epidemiology of mode of life", both refer to the 
Planes of emergence and modes of health.

\begin{tabular}{llll}
\hline $\begin{array}{l}\text { Planes of } \\
\text { emergence }\end{array}$ & $\begin{array}{l}\text { Categories } \\
\text { of non-health }\end{array}$ & Modes of health & Descriptors \\
\hline $\begin{array}{l}\text { Sub-individual } \\
\text { Individual }\end{array}$ & $\begin{array}{l}\text { Pathology } \\
\text { Disease } \\
\text { Disorder } \\
\text { Illness }\end{array}$ & $\begin{array}{l}\text { Normality } \\
\text { Normal health }\end{array}$ & $\begin{array}{l}\text { State } \\
\text { Signs \& symptoms }\end{array}$ \\
Collective & Pisk & Private health & Feeling \\
& Morbidity & Individual health & Status \\
Synthesis & Sickness & Healthiness & Measurement \\
& Health-disease-care & Situation \\
& & Social health & Forms (integral) \\
\hline
\end{tabular}

"illness" category, according to the distinction proposed under the Susser-Kleinman-Young line of thought. Note that in each of these cases the descriptors display a certain sense of antagonism: "health status" as the intent to objectify the individual mode of health and "health feeling" as the intimate, particular, private mode of health, which cannot be made public.

Within this scheme, it is also possible to situate the conventional epidemiological perspective (the epidemiology of risk factors), founded on an inductive logic with a probabilistic basis (Almeida Filho, 1997; Ayres, 1997). From this perspective, the health-disease object is reproduced as a specific concept, with risk production models based on the direct action or interaction of risk factors. In the epidemiological sphere of risk analyses, measurement-type quantitative descriptors (rates, coefficients) can deal with the subset's counterdomain [the sick population groups], equivalent to the population residue ( 1 - risk).

The notion of public health in the elder Canguilhem, which one can call "healthiness" in contrast with the idea of morbidity in traditional public health discourse, can have "health situation" as an efficient descriptor. Finally the modes of "social health", equivalent to the concept of sickness in interp retative medical anthropology, could be approached through Bibeau-Corin's systems of signs, meanings, and practices of Health ( $\mathrm{SmpH})$. Indeed, the SmpH theory provides the possibility of incorporating sickness into the health concept itself, to the extent that it sees the experience of sickness as a way of structuring the social representation of health by constructing subjectivity and the subject's relationship to the material and symbolic world.
A synthesis of this initial approach to the problem of theoretically defining Health is that one cannot speak of health in the singular, rather of various "healths", depending on the levels of complexity and planes of emergence at stake. Such an early conclusion is in line with Czeresnia's (1999) emphasis on the important difference between prevention and promotion regarding the pragmatic use of concepts of Health. However, this issue is best depicted in Sol Levine's insight concerning levels of "health reality", as in the following quote: "But what is heal th? It is, of course, not directly observable, but is inferred. Health is, first of all, a conceptual construct that we develop to encompass a range of different classes of phenomena [... in] three level s of reality: the physiological, the perceptual, and the behavioral" (Sol Levine, 1995:8).

At this still preliminary stage of exploration and theoretical formulation, there is no doubt that one must face a new family of objects, i.e., object-models not defined by their components, functional principles, and dimensions, which do not prove amenable to the production of knowledge by way of fragmentation (hence, objects adverse to analytical processes). Such synthetic models tend towards a new degree of formal ascension to become metasynthetic objects, constructed for (and by) reference to the facts produced by the so-called Health Sciences.

\section{Further comments}

Before concluding, two questions are in order by way of an overall justification for this essay: Why not adopt the health-as-absence-of-dis- 
ease perspective, as almost everyone has done? Why seek to construct a positive health concept? Why propose a General Theory of Health rather than a perhaps more realistic unified theory?

The first question has important practical and theoretical consequences. Let us first look at its practical side. Intuitively, it is not easy to propose interventions in a void, aimed at transforming situations that determine absences, powers, or virtualities. To consolidate subj ects' resistance and resilience towards the DIS Complex, to induce an increase in what has been termed social capital (Kawachi, 1999; Kawachi et al., 1999), to reinfore the human ties that produce quality of life in daily life through social support networks (Kaplan et al., 1977), in short, to effectively achieve the much-lauded health promotion, we need a specific construct to designate Health (Noack, 1987). This means constructing a positive object-model for knowledge and intervention rather than a negative object, a mere conceptual residue from explanatory modes of biological and social life based on their logical opposite.

The health-as-absence-of-disease perspective, albeit conceptually comfortable and methodologically feasible, cannot fully deal with the processes and phenomena referring to life, health, sickness, suffering, and death at any of the levels of reality identified above by Levine (1995). Just as the whole is alwaysgreater than the sum of its parts, health is much more than the absence or inverse of sickness. It is a crucially interesting logical problem, to be solved by overcoming the antinomy between health and sickness inherited from the traditional biomedical model.

Let us return for a moment to Tal cott Parsons. In his last work (Parsons, 1978), a detailed analysis of the relationship between social practice and the human condition (and a littleknown and poorly evaluated work, even among social theoreticians), this author resumes the theme of Health, defining it "as a symbolic circulating medium regulating human action and other life processes", in the context of a curious analogy with the economic concept of wealth (health $=$ wealth). Like currency, Health does not constitute a value per se, but does in fact become a value in exchange processes. Thus, according to Parsons, Health is not a capacity that is found in the body, nor even does it refer to the individual organism, rather it is a mediator in the interaction between social subjects. Health is not something that can be "stored"; it only exists while it circulates, when it is "enjoyed". Health, as stated succinctly by Parsons (1978:69), "is the tel eon omi c capacity of an in- dividual living system... the capacity to cope with disturbances... that come ei ther from the internal operations of the living system itself or from interaction with one (or) more of its environments". Health is thus not the inverse or absence of sickness; and sickness (always illness, according to Parsons) should be the "obverse" of health.

The second question haunts other contemporary scientific fields. The basic difference between a unified theory and a general theory is that the former is postulated as a global form of exclusive and all-encompassing explanation, valid for all levels and contexts, while a general theory implies alternative modes of understanding, respecting the complexity of the objects and the plurality of different scientific approaches to an interdisciplinary problem.

The epistemological critique expounded in this paper was highly useful for establishing the central problem of levels of complexity and planes of emergence, indicating that healthdisease phenomena cannot be defined as essentially an individual-clinical or subindividual-biological issue. In addition, the objects of Health are polysemous, plural, multifaceted, transdisciplinary, simultaneously ontological and heuristic models capable of traversing (and being traversed by) spheres and domains referring to different levels of complexity.

I wish to conclude by leaving a hint of doubt: and what if Gadamer is right? Perhaps health is more a question of life than of science; if so, then it would not make sense to construct it as the object of even relatively objective knowledge. It may be that metasynthetic and sensitive objects like Health and the DIS Complex can only be found beyond proud science and vain philosophy.

Despite this hint of doubt, it is up to us to proceed. Based on this preliminary essay, we can test hermeneutic methodologies for investigating scientific discourses, assuming them no longer as an external object of inquiry, but seeking to retrace the steps of the thematic investigation of health itself and its concerns, a reflexive research process. The reflexivity, sensitivity, and transdisciplinarity of the complex object Health can thus be incorporated into what is still a relatively atypical approach, even within a paradigm of complexity. In this tentative process of constructing a General Theory of Health, it will certainly be necessary to transcend the disciplinary borders between the socalled "natural" and human sciences in health. Thus, perhaps the health sciences, both human and natural, may actually deserve the title of Life Sciences. 


\section{Acknowledgments}

Study funded by the Brazilian National Research Council (CNPq) with Fellowship Award 520.573/95- 1 and Grant 463.855/ 00-0. Maria Thereza Ávila and Fernanda Tourinho Peres contributed extensively to the literature review, Jairnilson Paim, Maurício Lima Barreto, and Lígia Vieira da Silva collaborated with critical reading of the various versions of the paper, and Denise Coutinho proofread style and wording.

\section{References}

ABED, L. C., 1993. La Enfermedad en la Historia. Córdoba: Dirección General de Publicaciones, Universidad Nacional de Córdoba.

ALMEIDA FILHO, N., 1997. A Clínica e a Epidemiologia. 2a Ed. Rio de Janeiro: APCE/ABRASCO.

ALMEIDA FILHO, N., 2000. What does the word “health" mean? Cadernos de Saúde Pública, 16: 300-301.

ALMEIDA FILHO, N., in press. O conceito de saúde: Ponto-cego da epidemiologia? Revista Brasileira deEpidemiologia.

ALM EIDA FILHO, N.; CORIN, E. \& BIBEAU, G., unpublished manuscript. Signs, Meanings and Practicein Mental Health: Part II. Methodological Application. TheBahia Study.

AYRES, J. R., 1997. Sobre o Ri sco - Para Compreender a Epidemiologia. São Paulo: Editora Hucitec.

BERLINGUER, G., 1988. A Doença. São Paulo: Centro Brasileiro de Estudos de Saúde/ Editora Hucitec.

BIBEAU, G. A., 1988. Step toward thick thinking: From webs of significance to connections across dimensions. Medical Anthropology Quarterly, 2:402-416.

BIBEAU, G., 1994. Hay una enfermedad en las Américas? Otro camino de la antropología médica para nuestro tiempo. In: Cultura y salud en la construcción de las Américas, VI Congreso Colombiano de Antropología, Anales, pp. 44-70, Bogotá: Instituto Colombiano de Cultura, Universidad de los Andes.

BIBEAU, G. \& CORI N, E., 1994. Culturaliser l'épidémiologie psychiatrique. Les systèmes de signes, de sens et d'action en santé mentale. In: MarcAdélard Tremblay ou la construction del'anthropologi equébécoise (P. Charest, F. Trudel \&Y. Breton, dir.), Quebec: Presses de l'Université Laval.

BIBEAU, G. \& CORIN, E., 1995. From submission to the text to interpretative violence. In: Beyond Textuality. Asceticism and Violence in Anthropological Interpretation. Approaches to Semi otics Series (G. Bibeau \& E. Corin, ed.), pp. 3-54, Berlin: Mouton de Gruyter.

BOORSE, C., 1975. On the distinction between disease and illness. Philosophy and Public Affairs, 5:49-68.

BOORSE, C., 1977. Health as a theoretical concept. Phi losophy of Science, 44:542-573.

BOORSE, C., 1997. A rebuttal on health. In: What is Disease? (J. Humber \& R. Almeder, ed.), pp. 1-134, New Jersey: Humana Press.
CANGUILHEM, G., 1966. Nouvelles Réflexions sur le Normal et le Pathologique. Paris: P.U.F.

CANGUILHEM, G., 1978. O Normal eo Patológico. Rio de Janeiro: Forense Universitária.

CANGUILHEM, G., 1990. La Santè: Concept Vulgaire et Question Philosophique. Toulouse: Sables.

CAPONI, S., 1997. Georges Canguilhem y el estatuto epistemológico del concepto de salud. PhysisRevista deSaúde Col etiva, 4:287-307.

CHAVES, M., 1972. Saúde \& Sistemas. Rio de Janeiro: Editora da Fundação Getúlio Vargas.

CLAVREUL, J., 1980. A Ordem Médica. São Paulo: Brasiliense.

CLOUSER, K.; CULVER, C. \& GERT, B., 1997. Malady. In: What is Disease? (J. Humber \& R. Almeder, ed.), pp. 175-217, New Jersey: Humana Press.

CORIN, E., 1995. The social and cultural matrix of health and disease. In: Why are some People Heal thy and others Not? The Determinants of Health of Populations (R. G. Evans, M. L. Barer \& R. Marmor, ed.), pp. 93-132, Hawthorn: Aldine de Gruyter.

CORIN, E.; BIBEAU, G. \& UCHÔA, E., 1993. Éléments d'une sémiologie anthropologique des troubles psychiques chez les Bambara, Soninké et Bwa du Mali. Anthropologi eet Sociétés, 17:125-156.

CORIN, E. \& LAUZON, G., 1992. Positive withdrawal and the quest for meaning: The reconstruction of experience among schizophrenics. Psychiatry, 55: 266-281.

COSTA, N., 1989. Ensaio sobre os Fundamentos da Lógica. São Paulo: Editora Hucitec/EDUSP.

CULVER, C. \& GERT, B., 1982. Philosophy in Medicine. Oxford: Oxford University Press.

CZERESNIA, D., 1999. The concept of health and the difference between prevention and promotion. Cadernos de Saúde Pública, 15:701-709.

ENGELHARDT, T., 1975. The concepts of health and disease. In: Evaluation and Explanation in the Bi omedical Sciences ( T. Englehardt \& S. F. Spicker, ed.), pp. 125-141, Dordrecht: D. Reidel Publishing.

FIELD, D., 1976. The social definition of illness. In: An Introduction to Medical Sociology (D. Tuckett, ed.), pp. 334-366, London: Tavistock.

FOU CAULT, M., 1963. Naissance de la Clinique: Une Archéol ogie du Régard Médical. Paris: P.U.F.

FOUCAULT, M., 1976. Mental IIIness \& Psychology. New York: Harper \& Row. 
FULFORD, K. W. M., 1994. Closet logics: Hidden conceptual elements in the DSM and ICD classifications of mental disorders. In: Philosophical Perspectives on Psychiatric Diagnostic Classi fication (J. Sadler, M. Schartz \& O. Wiggens, ed.), pp. 211232, Baltimore: Johns Hopkins University Press.

GADAMER, H. G., 1993. The Enigma of Health. Berkeley: Stanford University Press.

GONÇALVES, R. B. M., 1992. Práticas de Saúde: Processo de Trabal ho eNecessidades. Cadernos CEFOR - Textos 1. São Paulo: Centro de Formação dos Trabalhadores da Saúde.

GOOD, B., 1994. Medicine,Rationality, and Experience. An Anthropological Perspective. New York: Cambridge University Press.

GOOD, B. \& GOOD, M. J., 1980. The meaning of symptoms: A cultural hermeneutic model for clinical practice. In: The Relevance of Social Science for Medicine (L. Eisenberg \& A. Kleinman, ed.), pp. 165-196, Dordrecht: D. Reidel Publishing.

GOOD, B. \& GOOD, M. J., 1982. Toward a meaningcentered analysis of popular illness categories: 'Fright IIIness' and 'Heart Distress' in Iran. In: Cultural Conceptions of Mental Health and Therapy (A. J. Marsella \& G. M. White, ed.), pp. 141166, Dordrecht: D. Reidel Publishing.

HELLER, A., 1986. La Teoria de las Necessidades en Marx. Barcelona: Península.

HESSLOW, G., 1993. Do we need a concept of disease? Theoretical Medicine, 14:1-14.

HUMBER, J \& ALMEDER, R. (ed.), 1997. What is Disease? New Jersey: Humana Press.

INECOM, 1993. The International Network for Cultural Epidemiology and Community Mental Health. Montreal: World Health Organization Collaborating Centre for Research and Training in Mental Health.

KAPLAN, B.; CASSEL, J . \& GORE, S., 1977. Social support and health. Medical Care, 15:47-58.

KAWACHI, I., 1999. Social capital and community effects on population and individual health. Annals of the New York Academy of Sciences, 896:120-130.

KAWACHI , I.; KENNEDY, B. P. \& GLASS, R., 1999. Social capital and self-rated health: A contextual analysis. American Journal of Public Health, 89:1187-1193.

KLEINM AN, A., 1980. Pati ents and Healersin the Context of Culture. Berkeley: University of California Press.

KLEINM AN, A., 1986. Concepts and a model for the comparison of medical systems as cultural systems. In: Concepts of Health, IIIness and Disease. A Comparative Perspective (C. Currer \& M. Stacey, ed.), pp. 29-47, Oxford: Berg Publishers.

KLEINM AN , A., 1988. The IIIness Narratives: Suffering, Healing \& The Human Condition. New York: Basic Books.

KLEINM AN, A., 1992. Local worlds of suffering: An interpersonal focus for ethnographies of illness experience. Qualitative Health Research, 2:127-134.

KLEINMAN, A.; EINSENBERG, L. \& GOOD, B., 1978. Culture, illness, and care. Clinical lessons from anthropologic and cross-cultural research. Annals of Internal Medicine, 88:251-258.

LAKOFF, G., 1993. Women, Fire, and Dangerous Things. Berkeley: University of California Press.
LEVINE, S., 1995. The meanings of health, illness and quality of life. In: Quality of Lifeand Health.Concepts, Methods, and Applications (I. GuggenmoosHolzmann, K. Bloomfield, H. Brenner \& U. Flick, ed.), pp. 7-14, Berlin: Blackwell WissenschaftsVerlag.

MASSÉ, R., 1995. Cultureet Santé Publique. Montreal: Gaetan Morin.

MURPHY, E., 1965. The Logic of Medicine. Baltimore: Johns Hopkins University Press.

NOACK, H., 1987. Concepts of health and health promotion. In: Measurement in Health Promotion and Protection (T. Abelin, Z. Brzezinski \& V. Carstairs, ed.), WHO Regional Publications, European Series 22, pp. 5-28, Copenhagen: World Health Organization.

NORDENFELD, L., 1987. On the Nature of Health. Dordrecht: D. Reidel Publishing.

NORDENFELD, L., 1993. Quality of Life, Health and Happiness. Aldershot: Avebury.

OXFORD DICTIONARY, 1968. Oxford English Dictionary. New York: Oxford University Press.

PAIM, J., 1996. A situação de saúde no Brasil e os modelos assi stenciais. In: IV Encontro Especial da Sociedade Brasileira para o Progresso da Ciência (SBPC), Anais, pp. 249-253. Feira de Santana: SBPC.

PARSONS, T., 1951. TheSocial System. New York: Free Press.

PARSONS, T., 1964. Social Structureand Personality. New York: Free Press.

PARSONS, T., 1975. The sick role and the role of the physician reconsidered. MMFQ/Health Sociology, 53:257-278

PARSONS, T., 1978. Action Theory and Human Condition. New York: Free Press.

PEREZ-TAMAYO, R., 1988. EI Concepto de Enfermedad. México, DF: Fondo de Cultura Económica.

PÖRN, I., 1984. An equilibrium model of health. In: Health, Disease, and Causal Explanationsin Medicine (L. Nordenfeld \& J. Odelstad, ed.), pp. 225238, Dordrecht: D. Reidel Publishing.

PÖRN, I., 1993. Health and adaptedness. Theoretical Medicine, 14:295-303.

SAM AJA, J., 1994. Epistemología y Metodología. Buenos Aires: EUDEBA.

SAM AJA, J., 1997. Fundamentos Epistemológi cos de Ias Ciencias de la Salud. Doctoral Thesis, Rio de Janeiro: Escola Nacional de Saúde Pública/Fundação Oswaldo Cruz.

SUSSER, M., 1973. Causal Thinking in the Health Sciences. New York: Oxford University Press.

TEM KIN, O., 1963. The scientific approach to di sease: Specific entity and individual sickness. In: Scientific Change: Historical Studies in the Intellectual, Social, and Technical Conditions for Scientific Discovery (A. Crombie, ed.), pp. 629-647, New York: Basic Books.

YOUNG, A., 1980. The discourse on stress and the reproduction of conventional knowledge. Social Scienceand Medicine, 148:133-146.

YOUNG, A., 1982. The anthropologies of illness and sickness. Annual Reviews of Anthropology, 11:257285. 


\section{Debate on the paper by Naomar de Almeida Filho}

Debate sobre o artigo de Naomar de Almeida Filho

Roberto

Briceño-León

Laboratório de Ciencias

Sociales, Universi dad

Central deVenezuela

Caracas, Venezuela.

Health and the lack thereof
In his interesting article, Naomar Almeida FiIho complains that sociology has failed to provide an answer to the search for a general theory of health, but does a general theory of health really make sense?

Health is a polysemous notion. Its multiple meanings are hidden or disguised under the cloak of the idea that when it is missing, specific facts like diseases are expressed, but that when it is present, it displays more desires and illusions than realities capable of embodying a general theory.

Health is like one of those signifiers that the unconscious, in the Lacanian view (Lacan, 1966), employs to add successive and mutable meanings. And this is what happens when one attempts to state - reasonably too much so that heal th is not only "the absence of disease", and one postulates "maximum well-being" as a positive definition. Maximum well-being is a signifier full of multiple meanings, since it embodies a fleeting desire, a fantasy quite appropriate to the contemporary quest for happiness, which can take the form of free-of-everything (salt, sugar, etc.) diets, body worship through exercise training, the resurgence of new and old religions, and the narcissism of romantic love. Still, is health happiness?

It is interesting that Almeida Filho has to appeal to disease to define health, when such erudite and well-argued positions from Harvard, with A. Kleinman, and Montreal, BibeauCorin, also refer systematically to disease. Whether the concept is disease, illness, or sickness, the issue is infirmity of the body, the conscious, or social relations. One does not speak of health, but of infirmity. Health is what is lost somewhere and is defined more by its hollowness than its content.

Disease defines health, just as death defines life. As written by Wittgenstein (1973), it is not that death leads us to silence, since death is not part of life. Death, perhaps rather as conceived by Heidegger (1962), gives transcendence to life; the awareness of death gives impulse to transcendent actions and to the concept of health as this goal of delaying death by extending life expectancy, or that pushes away its traits, like disabilities, which are announced during life.

Both disease and illness are always social constructs, whether derived from witchcraft or scientific knowledge, but which are also a part of a cultural context that mediates them and gives them meaning and force. Or that gives them legitimacy to link to other social relations, to justify absence from work or claim reimbursement from one's insurance company. Yet they are also silences that speak, telling of what is yearned for but not named.

Yet health is all the more a construct in that it is located in the shifting terrain of desire. It is a construct of the way of understanding the body, its vigor and weakness, its odors and stenches, its presence and finitude. But it is a construct where social goals al ways play a role, defined as historically and socially possible, as well as the individual desires forged in the imagination. The individual scale of health expresses the ideal self (idealich) that has been forged in the social context and that provides the support to be expressed in beauty, Iongevity, enjoyment, or quality of life as the exercise of potential ities, in the sense proposed by Sen (1973). Heal th is another way of expressing individual and social aspirations in a historical moment, but in a very dramatic dimension, since it is part of our social narcissism, which tends to shun reality, always fleeing towards the imaginary. That is why health, at the imaginary level, can take the form of individual economic success, social revolution, or nirvana.

Health as a general theory does not exist. There are only historical claims, demarcating what we are missing. Gadamer is right when he considers health elliptic. Almeida Filho stalks it, queries it, but doubts. Nevertheless this is the razor's edge on which one must move forward. Health is our desire for completeness, our narcissism, our endless quest to fill the gap that makes us mortals. There are threats, there are promises, there are changes, there are losses. But everything that is reached is ephemeral, everything is imaginary and at the same time real. Thus any presumption of a general or life sciences theory should labor to grasp thismovement, this permanent and unattainable trend that longs to be health when it longs to be something more than the simple absence of infirmity. Thus health should have as an essential component the acceptance of what is missing, the incompleteness and imperfection that we are, since the best of all healths will never save us from infirmity and death. And death must be an essential component of any life science, because it gives meaning to the mutant tempo- 
rality that we are. Because this is the time of our being, and thus the poet portrays us: "Yours is the time through which your body passes/with thetrembling of the world,/time,not your body.../ Yours is the touch of hands, not the hands; /the light filling your eyes, not the eyes;/perhaps a tree, a bird you watch,/the rest is beyond./We only bear the time of being alive/between thelightning and the wind;/thetime in which your body spins with the world,/today, the cry of the miracle;/the flame that burns with the candle, not thecandle..." (Montejo, 1996:162).

HEIDEGGER, M., 1962. Ser y Tiempo. Madrid: José Gaos.

LACAN, J., 1966. Écrits. Paris: Éditions du Seuil.

MONTEJO, E., 1996. Antología. Caracas: Monteavila Editores.

SEN, A., 1993. Capability and well-being. In: TheQuality of Life (K. Nusbauun \& A. Sen, ed.), pp. 30-54, Oxford: Oxford University Press.

WITTGENSTEIN, L., 1973. Tractatus Logico-Philosophicus. Madrid:Tierno Galvan.
Miguel Kottow

Departamento de Filosofia, Facultad deFilosofia

y Humanidades, Universidad deChile Santiago de Chile, Chile.
Public health and individual morbidity

It may be pertinent to speak of a health-disease dyad, but such pairing has its price. A dyad is more than just two of a kind; it implies a certain categorical opposition where one term excludes the other - either healthy or not healthy. The op posite of health is non-health (or "unhealth"), which may be disease, illness, sickness, or malady, so there is no real dyad unless we create one: health-morbidity. Whereas disease, illness, and sickness form a family of concepts in need of definitions, the German Krankhei or its Spanish equivalent enfermedad are polysemous and open to hermeneutic interpretations. The differences are cul tural, and translations only stress and distort the actual use of language. Too much emphasis is put on [arbitrary] definitions; what matters are the actions that such concepts denote and elicit.

There seems to be fair agreement that disease is a medical description of organismic disorders, subject to hard description and quantification aimed at achieving causal explanations and specific interventions, whereas illness is the experience of abnormality in form or function. Disorder and deviation necessarily refer to some standard of normalcy which may be described for the species (Boorse), although it seems more to the point that the individual constitutes his own standard of health/morbidity (K. Goldstein). Nevertheless, it is rarely acknowledged that feeling ill may lead to two different attitudes: unexplained, intolerable, and uncontrollable suffering that leads one to seek therapeutic assistance; or physical discomfort that is predictably temporary and expected to go away spontaneously. The difference is between suffering hematuria and having the flu, between having an illness and feeling sick. This important distinction needs a name and in fact has one in daily parlance: a person feels sick after eating spoiled seafood, or suffers from sea-sickness, or a pregnant woman feels morning sickness but knows she is not ill. All such cases of sickness will probably not lead the individual to seek medical advice. While illness leads one to seek medical help, sickness remains in the realm of bearable unpleasantness.

The habitual experience of sickness disowns Twaddle's suggestion that it is a social label assigned to individuals incapable of performing their roles in a normal way. If philosophy is not to interfere with the actual use of language (Wittgenstein), then sickness is a term that must preserve its everyday use, thus denying that society participates in defining morbidity. Rather, social forces analyze medical labeling of disease and decide upon pertinent strategies for insurance, medical care, subsidiary financing, and resource allocation. Medicine describes organismic disorders, while society evaluates them. In order to adequately fulfill their functions, public policies must find a fit between the scientific view of disease and the subjective experience of uncontrollable illness.

It is true that illness, medical definition of disease, therapeutic efforts, and social support are all culturally influenced, and social environments certainly play a central pathogenic role in many disorders. Nevertheless, it is the individual who experiences illness, and it is in the unique physician-patient encounter where disease is detected, labeled, and subject to appropriate treatment. All these experiences are of course value-laden, and it is a mistake to aim at value-free definitions in the health/morbidity complex. Bioethics has stressed that medical excellence depends on taking due notice of the subjective illness component. The clinical encounter, where ill ness is presented and disease is recognized, is a strictly medical situation, although strongly influenced by many extramedical factors.

Where does this perhaps excessively detailed analysis leave the concept of health? Is it 
not, after all, the default state of any organism which has no [detectable] morbidity - Bichat's silence of the organs? Health is not an experience, nor is it a recognizable state of the organism, for medicine can probe and certify the normalcy of certain functions, but never exhaustively of the organism as a whole. Medical efforts ai $m$ at eliminating disease, or preventing it when a person is vulnerable: its task ends when disease is removed (Gadamer). If health could be described and medicine were to be charged with protecting it, we would be opening the doors to an incommensurable and undesirable medicalization of human life, far beyond what already occurs. All the more so if we give in to the temptation of creating total health-disease objects with hierarchical levels, for then health and disease become an endless laboratory exploration in the sub-individual realm.

If health remains a negative idea, it ceases to sustain health care programs and public health policies, which appear to become conceptually void and fall into pragmatic sterility. Does this also make public health a non-entity? Certainly not. Morbidity in all its forms is a state of individual organisms. Public health cannot be a state, it rather must be seen as an environmental process concerned with creating social and ecological conditions of such quality as to hel $p$ citizens avert morbidity and become less vulnerable to external noxae. More than a positive concept of individual health, we need to act upon socially induced pathogenic factors and create living conditions that allow single organisms to live in biologically and anthropologically friendly environments, free from the risks of social and ecological toxicity. We might gain some distinctness and clarity of concepts if we spoke of public health as a social strategy to reduce the risks of individual morbidity - disease, illness, and sickness according to agreed-upon definitions. Public health acts at the collective level to control factors that cause disease and influence the organism's well-being from outsi de the individual, whereas medicine is less concerned with health than with treating derangements that occur within the individual. If more efficient public health policies lead to less individual morbidity, we will have thereby discovered a true and useful dyadic relationship.
Luis David
Castiel

Departmento de Epidemiologia e Métodos Quantitativos em Saúde, Escola Nacional de Saúde Pública, Fundação Oswaldo Cruz, Rio deJaneiro, Brasil.
To be necessarily precise... or precisely necessary?

"We end up shaping the world as if it allowed itself to be reduced, here and there, to intell igible elements. Sometimes our senses are sufficient for this purpose, and other times more ingenious methods are employed, but empty spaces are left. The attempts remain full of gaps (...)" (Paul Valéry, 1998).

Once again, Naomar de Almeida Filho has produced an essay in which his undeniable talent as scholarly bricoleur emerges clearly, with his skillfully fertile innovation in the field of philosophical reflection on health. For those who are unaccustomed to treading on such arid ground, it is a landscape which can give one the impression of dangerously approaching innocu ousness and/ or irrelevance in the face of the instrumental pressures increasingly characterizing the health domain. Yet in this case the author has constructed a vigorous and stimulating conceptual and epistemological framework, under the preliminary format of what he refers to as a "General Theory of Health", wisely explaining beforehand the caution required for such a daunting task.

The synthesis is extremely hel pful in the presentation to the socio-anthropological (functionalist, phenomenological, semeiologic) and epistemological approaches as a prior review to the proposed systematization of 'modes of health' that concludes the essay.

My modest attempt to contribute to the debate is based on two points which tend to juxtapose: (a) the question as to whether "health [can] be treated as a scientific concept" and (b) the "hint of doubt" mentioned by the Bahian epidemiologist as to the possibility of Gadamer being right. In other words, it becomes compelling that heal th is something individual, private, unique, and subjective [indeed, in my view, not a very simple conclusion, contrary to what Almeida Filho contends, since if the conclusion were simple it would not entail the serious implication of making the 'scientificization' of the object health problematic].

On this point, I believe that it is appropriate to consider the uncomfortable possibility of a fleeting and simultaneous "coexistence" of aspects that are defined/undefined, precise/ imprecise, accessible/ inaccessible, unknown - potentially cognoscible/ unknowable - incognoscible, in the demarcation of what health finally is. As Moles (1995:45) puts it, "the human spirit is fluid in its functioning, ambiguous in its con- 
cepts, and vague in its definitions". According to the latter author, one of the categories of the imprecise relates to "phenomena that are vague in essence (author's emphasis), or in which the concepts used to enu nciate them are themselves vague, perhaps inadequate, but which are the only ones we haveavailable" (Moles, 1995:19). In short, the words of Moles (or Valéry's epigraph) appropriately represent my impressions while reading Almeida Filho's propositions.

More specifically, I wish to highlight several issues for discussion on this stimulating article:

The preliminary establishment of a "semantic demarcation", or correspondence between the terms used in English and Portuguese (disease = patologia, disorder = transtorno, etc.) is not without side effects. We know that words have the stubborn "property" of unmasking themselves in the face of our attempts to circumscribe them in stabilized meanings. Visibly, as in Figure 1, to use patologia to mean both "pathology" and "disease" may lead to misunderstandings. I do not believe that to refer respectively to the "Canguilhemian (i.e., sub-individual) sense" or to the "structural (individual) register" satisfactorily resolves this focus of potential equivocation.

I believe that as a scholar of etymology (note his timely editorial in Cadernos de Saúde Pública on the etymology of "health"), Almeida Filho should consider that one cannot heedlessly conduct a semantic demarcation of doença as the equivalent of "sickness", relating to the collective realm. Doença [as disease] is consecrated not only by common sense, but by the biomedical literature. The Portuguese-language term doença originally comes from the Latin dolentia, which in turn comes from dolere, to hurt [or to grieve, as in the English dolent - T. N.]. In this case, Gadamer's argument is imperious, since pain is normally referred to at the individual level as being personal and inalienable, with a high level of "subjectivity".

The article was not intended to analyze in extensive detail the conditions for possible demarcation of "modes of health" or the respective "descriptors". Even so, at first glance, some specific aspects appear to demand greater clarification and elaboration. An example is the mode of health referred to as "1 - risk", something which, by the way, appears to be conceptually frisky [a play on words by the discussant using risco, or risk, and arisco, i.e., frisky or undisciplined - T. N.]... If epidemiological risks are measured and indicated by way of numerical values, what is the cut-off point which clearly defines which groups are actually at risk and which are not? How does one deal with the more elderly age brackets, increasingly present in the Brazilian population pyramids, where risks appear to proliferate with the expansion of vulnerabilities arising from aging?

It is appropriate to recall here that the discussions on risk extend beyond the strictly quantitative epidemiological approaches. The notion of "risk" is, pardon the term, proteiform, i.e., it can involve various aspects: economic (unemployment, poverty), environmental (various types of pollution), relative to personal conduct ("improper" ways of eating and drinking, not exercising), interpersonal (ways of establishing and maintaining amorous and sexual relations), and "criminal" (events linked to urban violence) (Lupton, 1999). All of these "risks" "ferment", mixing and overflowing into the cultural realm, becoming signs and symbols

In short, the "experience" of risk plays an increasingly active role in the shaping of identity matrices and in the formation of subjectivities, prone to interpretations, amenable to approaches by $\mathrm{SmpH}$. In this sense, SmpH descriptors are linked not only to the non-health category "sickness", but also to "risk" as "social perception". What name should be used for this category? (danger, threat? - and in Portuguese? ameaça, perigo?) Is it appropriate to baptize it? How does one deal with the antagonism between the "health feeling" - an aspect that assumes an "intimate, particular, private[mode]... which cannot be made public" and "health status", which seeks to "objectify the individual mode of health"?. Furthermore, how can one refer to something as a "descriptor" when it is considered indescribable, i.e., that which "cannot be made public"? Perhaps, at best, it may only be "describable" in literary or poetic terms, but this is not the realm of the current discussion

Two further observations may be superfluous, especially since they relate to incidental comments in the essay:

Strictly speaking "Lakoff's prototypes" are not "Lakoff's"... In fact, this theory of categorization originates from the so-called "theory of basic level prototypes and categories" conceived by Eleanor Rosch and colleagues, as indicated by Lakoff himself (1987) in the study cited by Almeida Filho. Since the theory was presented very succinctly, clearly in keeping with the purpose of Almeida Filho's article, I will take this priceless opportunity to present a detailed description, given the relevance of these ideas (see Castiel, 1999).

As Almeida Filho states so well, there are circumstances in which no property, attribute, 
or characteristic is sufficient or necessary to define (in accordance with formal categorical logic) the case as belonging to the category. There are other modes of categorizing, based on criteria of familiar similarity, centrality, and prototypicality. These modes are anterior to the acquisition of logical-formal thinking. Such ideas were developed and systematized by the linguist Eleanor Rosch (1978) and colleagues in a general theory, based on empirical studies that challenged the classical point of view of categorization.

According to the formal/classical theory, no member of a category holds any primacy over others, since the aspects that define elements belonging to a given category are shared by all the members. Rosch (1978) showed in studies on the categories of color in the Dani language in New Guinea, which has two basic categories of color (mili - for dark, cold shades and mola - for light, hot shades) that there is an inclination or trend by individuals to choose given examples of the mola colors. In other words, they are considered prototypical - more representative than the others. In other words, there are asymmetries (prototypical effects) between members of the category and asymmetrical structures within the categories. Another example: in relation to the "bird" category, studies have shown that individuals indicate canaries and chickens as more representative of the category than penguins and ostriches.

It is important to emphasize that the categorical structure plays an essential role in the processes of reasoning and constitution of concepts. Under many circumstances, prototypes act as various types of cognitive points of reference and form the basis for inferences.

There also occur what are called "basic level effects" (Rosch, 1978). That is, there are levels that are more intelligible and prone to conceptualization than others. For example: basic level categories tend to be perceived better "snake" is grasped better than the hierarchically superior level "reptile" or the subordinate level "pit viper" or "boa constrictor".

Ferreira (1996) conducted an investigation that attempted to determine whether the theory of prototypes and centrality could be verified in samples with in the Brazilian context. $\mathrm{His}$ results corroborate the consistency of the work by Eleanor Rosch's group.

There is evidence that the categories we erect are heterogeneous, beginning with their cognitive origins. Human capacities to determine them are relational and also depend on our history of reciprocal effects with the world, that is, they simultaneously involve an inter- acting multiplicity of biological, cultural, and social elements. Categorizing skills appear more objective and accurate when referred to the basic level.

In short, categories depend on the ways in which individuals act with objects - how they perceive, construct images, organize information, and behave in relation to them. Basic level categories thus possess different properties from the others. They are amenable to characterization by means of images or motor actions. For example, the concept of "chair" is easier to conceive than that of "furniture" (Lakoff, 1987).

It is important to highlight that fuzzy logic as originally developed by Lotfi Zadeh does not exactly consist of an alternative logic that goes beyond the categorical logic that presides standard set theory. In broad terms, Zadeh (1965) conceived an ingenious perfection of standard set theory to model categories that allow for gradation - even describable by continuous "variables". In a classic set we have dichotomous aspects (either one is inside the category - 1 ; or outside it - 0 ); in a fuzzy set, as defined by Zadeh, it is possible to consider intermediate values between 0 and 1 . Thus, the Rosch prototype theory does not appear to me to be amenable to immediate understanding by such logic, as Almeida Filho suggests.

The most recent edition of the standard Brazilian dictionary Aurélio (1999) presents the definition for "obverse" in the realm of logic as something resulting from obversion, that is, "a valid immediate inference for any type of categorical proposition obtained by changing the quality of the proposition and replacing the predicate with its complement. Thus all $\mathrm{S}$ is $\mathrm{P}$, by obversion, will be no $S$ is non-P". We can thus "push the argument" and obversely commit the following "deduction": if all health is the absence of disease, no health is thus the presence of disease?! One clearly perceives the weakness and impropriety of this proposition. This proposition of the reductio ad absurdum type illustrates an improper exercise in formal logical reasoning in the field of health and life, which should be used with extreme caution, since the results may befallacious.

In a word, the purpose of this commentary was to emphasize that along with the progression in attempts to provide intelligibility to our objects of study, we should consider the possibility that there may be unattainable dimensions in this rationalist thrust that are proper to contemporary Western thought. For example, what is the "precision" that can be reached by linking "planes of emergence", "categories of 
non-health", "modes of health", and "descriptors" within these labyrinthine domains that may perchance be health (whether in the singular, or in the plural, as "healths"). If it is necessary (insofar as possible...) to make our objects of study more precise in order for the rationalist device to work, how should we proceed when we fail to achieve any clarity or precision in distinguishing all these items?

Furthermore, how do we know, in our quest to demarcate objects, when we produce not object-models but create object-artifacts and reify and fetishize them? It is hard to say, I admit. Yet even agreeing partially with Almeida Filho that "it is up to us to proceed", it appears to me to be appropriate to question, gently and carefully, how much good it actually does us in terms of advancement in health knowledge and practices to pursue our impetus forward... I believe there are moments in which one should take a brief "puzzled pause" to attempt to get some idea of the effects/ results of our irrepressible drive to know and produce objects. On such occasions, even with some resistance, it is important to consider being penetrated (slow and easy, mind you) beyond a hint of doubt...

CASTIEL, L. D., 1999. A Medida do Possível. Saúde, Risco, Tecnobiociências. Rio de Janeiro: Editora Fiocruz/Editora Contracapa.

FERREIRA, A. B. H., 1999. Novo Aurélio Século XXI: O Dicionário da Língua Portuguesa. Rio de Janeiro: Nova Fronteira.

FERREIRA, M. C., 1996. Estrutura interna de categorias semânticas e seus efeitos no processamento cognitivo. In: Psicologia e Mente Social. Construção de Teoriase Problemas Metodológicos (S. L. C. Fernandes \& M. Castanheira, org.), pp. 127143, Rio de Janeiro: Editoria Central da Universidade Gama Filho.

LAKOFF, G., 1987. Women, Fire, and Dangerous Things. What Categories Reveal about the Mind. Chicago: University of Chicago Press.

LUPTON, D., 1999. Risk. New York: Routledge.

M OLES, A. A., 1995. As Ciências do Impreciso. Rio de Janeiro: Civilização Brasileira.

ROSCH, E. \& LLOYD, B. B., 1978. Cognition and Cate gorization. Hillsdale: Lawrence Erlbaum Associates.

VALÉRY, P., 1998. Introdução ao Método de Leonardo da Vinci. Rio de Janeiro. Editora 34.

ZADEH, L., 1965. Fuzzy sets. Information and Control, 8:338-353.
Maria Cecília de Souza Minayo

Presidência, Fundação Oswaldo Cruz, Rio de Janeiro, Brasil.
Health as a scientific object and a theme for life

Almeia Filho's essay For a General Theory of Health: Preliminary Epistemological and Anthropologi cal Notes is surprising because of the level of intellectual energy with which the author launches into such a complex and difficult-to-define terrain, especially because he proposes to enter into the merit of defining a theory. Yet to construct a theory means first and foremost to believe that it is possible to explain or comprehend a phenomenon and the processes by which it is realized. It is this major undertaking that Almeida Filho embraces, surmounting the first difficulty by seeking to differentiate what might be called a Unified Theory from a General Theory.

Despite the inestimable value of the author's contribution for those who construct the theoretical practice of health, I see his work as an initial or preliminary approach, as he himself states it. This, because to construct a theory corresponds to the design of an organized system of propositions that are logical constructs and guide data acquisition and analysis, like the elaboration of concepts that are cognitive, pragmatic, and communicational artifacts bearing the theory's meaning. Beyond this, the idea of constructing a theory by constructing an organized whole has generally been applied more to the universe of disciplines and to the elaboration of schools of thought. To date, health has never been treated as either a discipline or school of thought, but rather as a field of knowledge and practices, within which there is a quest for scientific authority, technical capacity, and social power (Bourdieu, 1975); or as a living laboratory involving persons, equipment, experiences, roles, and strategies. (Latour \& Woolgar, 1979). In this sense, I consider it quite problematic to formulate a theory of health or health models. It is a different matter to theorize the health concept, which is ultimately the article's attempt.

At any rate, the paper corresponds to the discussion and to the enunciation of a possible theory, which leads us to ask whether the author intends to reflect on the health theme as a differentiated discipline. It behooves Almeida Filho to provide us with another act of his creative energy, tackling the challenges of delving deeply into the constitution of this general theory. This is crucial, since as one utilizes a set of logically related propositions, such a theory must provide an order, a system, an organiza- 
tional framework for thought, and its articulation with concrete reality, in an attempt to be understood by a community which follows the same path of reflection and action.

The concept-making undertaking is highly important and meritorious. The author presents a vast bibliographical review, ranging from seminal texts to contemporary studies, which he uses to relativize, chal lenge, or reaffirm the classics. And by blazing this intel lectual trail, Almeida Filho helps shed light on the object at hand, besides raising questions and hypotheses with great propriety and tracing a spiral path to the conclusion, which was the beginning of his queries, relativizing his own ideas. I confess that I am curious to see the sequel to the scientific construction of theory, since it differs from the limited line of what has been conceived to date in sciences (including the social sciences) concerning general theory.

I would like to raise several questions based on these initial observations. The first is that from the very beginning of the paper, in my opinion, Almeida Filho falls into a theoretical trap when he identifies as structuring dimensions of the scientific field of health "the socioanthropological dimension and the epistemological dimension". I ask: is the epistemological dimension structuring or is it part of the metaanalysis of theories? On the other hand, when he says that "despite recognizing its importance and founding role, the biological dimension will not be covered here, except insofar as it proves indispensable to clarify some specific issue in the health-disease models analyzed herein", is the author not losing a basic structuring dimension of the biological/social hybrid?

This is so true that the entire paper is permeated by the discourse on the biological, on phenomena and processes of falling ill, even when they appear in the widely varying semantic connotations presented by the author. What I am saying is that it becomes impossible to theorize about health/ disease without dealing simultaneously with aspects of the biological/ social hybrid. The exclusion of one element from the dyad jeopardizes the discussion.

There is one further problematic point in the path chosen by Almeida Filho, namely the fact that the texts on which the author bases his essay are the results of a long-standing, firmly based, and sophisticated reflection by the so-called Anglo-Saxon (especially North American) school of medical anthropology and sociology. The fact is that since their birth, these disciplines are firmly linked to knowledge of diseases, to the point that the term "health" follows in the wake of such knowledge and is thus launched into a reductionist semantic spectrum whose center is the attempt to avoid risk and maintain a vision of normality. Almeida Filho's paper itself, intended as a preliminary thrust towards a theory of health, fails to escape this theoretical entanglement, leaving until the end a slightly more open discussion (al beit still not systematized) based on the ideas of Canguilhem, Ricardo Bueno, and Samaja, together with some rather succinct observations on Kant and Gadamer, the latter emphasizing health at the individual level.

I do not know if I can contribute, but based on my theoretical reflections I will highlight two points. One pertains to the differentiation between the notion of health as a total social fact (Mauss, 1974) and the notion of health as a concept dealt with by a specific sector, constituting itself as a field of theoretical and health care practices and policies.

In the former case, health constitutes the core of human experience in society in its essential expression, since it means the synthesis of well-being, individual and social quality of life, cultural forms of preservation of existence and the species, and above all, collective efforts and disputes by differentiated social groups to establish parameters for what it means to be healthy. Obviously, as Almeida Filho recalls, within any society this mater-notion is constructed (by its intellectuals and institutions) through the interpretation and reinterpretation of the socio-political and existential processes of the entire society, through interactive dynamics. Lévy-Strauss (1967), studying primitive communities, noted that the well-being and pain we feel are socially constructed. In this sense, health is a good: social and collective; it is a social and political conquest; it is an expression: cultural and moral. This great Gift, which the poor confuse with wealth and the rich go to great lengths to make eternal, even defines a society's level of development and denotes the entire inter-play of its internal forces to achieve what are considered ideal parameters.

Indeed, to conceive of health from this point of view allows one to glimpse it as an object of knowledge linking biology both to anthropology and to specific policies or economics. In this world of life, health is not confused with the opposite of diseases, because the person can have specific problems affecting his or her body or mind and consider himself or herself heal thy. Disease can mean a privileged moment in life to achieve new healthy forms of growth and transcendence of personal limitations. In this regard it is important to quote 
Oliver Sacks, this amazing neurologist who devoted his life to exploring the world of the socalled "abnormal", who in the foreword to his book, An Anthropologist on Mars, states that "I am led to believe that it would be necessary to redefine the concepts of health/disease to vi ew them in terms of the body's capacity to create a new organization and a new order, adequate for its special disposition and modified according to its needs, rather than referred to a rigid 'norm'" (Sacks, 1995:18). Stated differently, health cannot be confused with complete well-being as proposed according to the classical definition by the World Health Organization or with normality or absence of disease, terms that govern medical logic. Disorders and diseases may have the paradoxical magic of revealing latent powers, displaying a creative wellspring, both individual and collective. While they can destroy pathways, they can also reveal new forms of transcendence unimagined in their absence. Hence the study of health is a topic delving into the complexity of organization of life and vital processes.

With regard to the concept of health as dealt with in health care and the theoretical practice of health, we fail to escape from the chalk circle of the biomedical paradigm, in which medical anthropology, collective health, and the entire medical system are enmeshed.

Thus Almeida Filho's paper merits great praise as part of an effort by numerous authors to unshackle the concept of health from the imbroglio of prevailing medical ideology. This effort is all the more crucial because the rapid development of biology, the adoption of new life styles, and the quest for environmental adequacy increasingly demand that the role of heal th (which is much broader and more complex than that of medicine) be differentiated from the biomedical model. Hence, even when based on the epidemiological morbidity/mortality profile, health proposals will be in harmony with that broad notion that society defines as its essential level of healthy existence and its development threshold. In addition, health's role must be based on new theories of complexity that deal with the notion of a certain level of instability and imbalance - and not that of normality - as essential for a healthy life. It is imbalance and imperfection that allow the effort and increased capacity to transcend previous thresholds in both individual and collective life. To be heal thy (or "to have health") will al ways be less to possess a state of normality and more to experience dynamics in existence that shift between disorder and order, from suffering to pleasure, from the capacity to

maintain an identity to the quest for unexpected growth and evolution.

I am certain that by proposing to introduce a theory of health, Almeida Filho intends to encourage us to rethink the paradigms that are our birthplace. Thus, his essay is an invitation to redefine such paradigms, seeking an enhanced approach to the phenomenon/ process that touches us so closely in our essential life and death dramas.

BOURDIEU, P., 1975. O campo científico. In: Pierre Bourdieu: Sociologia (R. Ortiz, org.), pp. 37-52, São Paulo. Editora Ática.

LATOUR, B. \& WOOLGAN, S. 1979. Laboratory Life. The Oral Construction of Scientific Facts. Beverly Hills: Sage Publications.

LÉVY-STRAUSS, C., 1967. Antropologia Estrutural. Rio de Janeiro: Editora Tempo Brasileiro.

MAUSS, M., 1974. Sociol ogia eAntropologia. v. I. São Paulo: EPU/EDUSP.

SACKS, O., 1995. Um Antropólogo em Marte. São Paulo. Companhia das Letras.

Dina Czeresnia

Departamento de Epidemiologia e Métodos Quantitativos em Saúde, Escola Nacional de Saúde Pública, Fundação Oswaldo Cruz, Rio de Janeiro, Brasil.
When I received this article by Naomar de Almeida Filho for comment, I recalled his paper entitled Current Problems and Perspectives in Epidemiological Research in Social Medicine, which provided the basis for the book Epidemiologia sem Números (Epidemiology Without Numbers). Written in the 1980s, the book was a major stimulus for reflection on epidemiological knowledge. I now perceive the same daring and generous characteristic of open-mindedness, debating even with himself, instigating, full of questions that incite us to think.

The article's goal is to conduct a preliminary evaluation of conditions allowing for a General Theory of Health, seeking to achieve the scientific construction of the object "health" through models of health and disease. The authors asks: Is a General Theory of Health feasible? Can health be treated as a scientific object? Does this undertaking involve an underlying philosophical problem or some essential epistemological obstacle? Is health a problem for science or a question that relates to life?

Such queries are now emerging acutely in the field of Collective Health, insofar as the notion of health promotion is increasingly identified as a perspective for intervention. Traditional Public Health models are based on a negative object, namely disease. How does one 
attain the inverse of this object? How does one construct positive models for knowledge and intervention in health without a specific theoretical construct defining health?

No scientific definition of health has been found to date. Understood as positivity, health has a meaning as broad as the very notion of life itself. When we refer to terms such as wellbeing and quality of life, linked to the idea of promoting health, we are in fact dealing with ontological questions like pleasure, virtue, and happiness. No matter how concise and transdisciplinary the attempt may be, there is no way of translating such life experiences into a scientific concept. From this existential perspective, health can only be defined as enunciated by Canguilhem (1990): “a common place concept or a philosophical question".

However, it is certain that the possibility of a philosophical health does not prevent one from taking health as a scientific object. Once again Canguilhem states (1990:35): “The recognition of health as the truth of bodies in theontological sense not only can but should admit the presence - as a margin and barrier, properly speaking - of truth in its logical sense, that is, science. Theliving body is certainly not an object, but for man, to live is also to know".

The health field has structured itself historically as linked to medicine, but from the point of view of Collective Health, the construction of truth in the logical sense is not limited to medicine. Collective Heal th is a prime space for opening to, and interface with, other areas that legitimately produce knowledge on health. However, no matter how integrated and broad this knowledge is, it does not fail to be a construction of truth in the logical sense, presenting itself "as a margin and a barrier" vis-à-vis the purpose of promoting the health of populations. What are the possibilities and limits of a field of knowledge and practices in dealing with an "object" that has an ontological meaning?

The complexity of the relationship between knowledge and existence is at the root of the difficulty in elaborating a positive concept of health. There is no theory capable of resolving the tension between life defined as subjective experience and that which is the object of sciences. Life Science defines health by its inverse, but without the inexorability of pain and suffering would a field of health make sense? Is the problem the fact that we do not work with positive concepts of health, or is it the implication of constituting a concept of disease in modernity, or even the form in which this concept is organized in practices that either favor or jeopardize life?

In this sense, the issue is not to solve the incompleteness of such knowledge but precisely to know how to accept it. I do not mean to disqualify such knowledge, but to qualify it in the sense of reinforcing the need to reflect on how to link health knowledge to the perspective of being truly useful for health promotion, that is, promotion of life. This involves affirming a complementary approach in action between mutually different languages, restating the importance of the role of philosophy, art, and politics.

In the solving concrete problems, knowing how to relativize the importance of knowledge without overlooking it is not a simple issue and is not a task for a specific field. Recognition of this limit implies a world view transformation which would certainly be translated specifically into profound changes in the logic of training human resources and formulating and operationalizing health practices.

The effort to construct scientific knowledge on health from a synthetic perspective is highly pertinent, seeking to integrate the multiple and complex dimensions of this object. But this transdisciplinary stance, as the author states, is organized around problems and not disciplines, demanding alternative and plural modes of understanding. From this broad view, would it not be contradictory to conceive a General Theory of Health? This, because it would not be one theory, but as many theories as there were alternative and plural modes of approaching this object.

CANGUILHEM, G., 1990. La Santé: Concept Vulgairee Question Philosophique. Paris: Sables.

Suely Deslandes Almeida Filho's essay is stimulating, as indeed is all of his work. More than as a text, let us ap-

Departamento de Ensino, Instituto Fernandes Figueira, Fundação Oswaldo Cruz, Rio de Janeiro, Brasil. proach it, as proposed by Anatol Rosenfeld (1985), as a "pre-text", a pretext for dialogue, happenings, and creation. The "text" will be this construction in movement, this totality of arguments, intensities, and intention. So let us tackle the debate.

By proposing a discussion on the prerequisites for formulating a General Theory of Health, Almeida Filho constructs a chain of argument concluding that available readings on the health object/field/concept are incapable of transcending the negative view of "health as 
absence of disease" and are hence unfit to construct a "Theory of Health". Naturally, this epistemological architecture is not new, in fact it is a common pathway for those who attempt to overcome a hegemonic paradigm or paradigmatic references, i.e., to seek to demonstrate that the explanatory power of certain theories has grown stale and that it is urgent to surmount them. This demands a profound critique "from the inside", i.e., demarcating the limitations of that theory or discipline's tools based on its own logic. Unfortunately, in this case sociology was taken for one of its schools, that of functionalism, and its authors were "evaluated" based on the operational concepts they use, considered "revealing" of their adherence to the negative view of health. The article loses sight of the theoretical context of each author quoted in the process, the many other readings from the domain of "sociology of health" itself, and the analysis of sociologists incorporated into the Collective Heal th debate (like Habermas, Bourdieu, and Giddens, to cite just those best known to the general public) which have certainly expanded the health concept and health praxis well beyond the equation "health =non-disease".

According to the author, anthropology, as expressed by the watershed of medical anthropology, has advanced in the effort at conceptualizing the DIS complex (disease, illness, sickness), but has failed to overcome the essential problem of prioritizing the ill individual's return to functioning with a normal and healthy life, without entering into the issue of what this normality is or the concept of health implied therein. Again, the rich dimension is often reduced to examining the basic concepts, and when the author recognizes in certain authors (Young and Bibeau-Corin, for example) a tendency to retrieve historical totality, a link between "the micro and the macro", a synergy between individual action and historical/cultural structures, he appears to find a new undertaking which in fact has been a daily issue for discussion in the Social Sciences for at least twenty years. Since so-called "radical" phenomenology had great influence on the field of health in the 1970s and now returns in adulterated fashion under the veil of methodological imprecisions, empiricist spontaneity, and studies erroneously referred to as "qualitative research", one can understand the author's concern.

The "inability" to overcome the negative vision of health still prevails. However, perhaps it is not a matter of viewing health as "the mere absence of disease-illness-sickness", hence an absence in terms of what health is in fact. But would the issue not be to recognize that the human experience of health has adhered to (not only dialectically but "ontologically") the very clash, the very struggle against death and the fear of pain, suffering, and destruction? Not as non-disease but as the unceasing struggle both against maculae (sanus) and at thesame timefor physical, psychological, and cultural integrity (salvus) (Almeida Filho, 2000), meanwhile, always noting the historicity of this confrontation, since as mentioned above the historicity of the object is the reality principle of Social Sciences (Passeron, 1995). Once removed from this dimension, does the concept of health not become watered down? This does not indicate ignoring the need, identified so well by Almeida Filho's paper, to undertake a reflection that overcomes the view of health as the mere inverse of disease.

In fact not only sociology but also the social sciences (and the so-called natural sciences as well) are insufficient for an understanding/ explanation of what health is, this polysemous and complex field/ object. Still, as postulated, we run the risk of basing the discussion of this insufficiency (which is rich because it makes dial ogue with other fields of knowledge indispensable) on an argument of incapacity, based on a rapid and external review of what these sciences are.

But the debate does not end here. It raises the bothersome question: is it possible to construct a General Theory of Health? And we would add to this: is it possible and desirable today to construct a General Theory? Many authors in Modernity have followed this enticing proposition, albeit in the form of a "unified theory". At any rate, therein lies the idea of a theoretical construct, hence a way-of-seeing, capable of explaining the concatenation/functioning/ organization of a set of phenomena or of the social order itself. The so-called "total theories" that circulated in the 19th century and survived the 20th century articulated disciplinary knowledge and even provided a number of multidisciplinary propositions. They made an effort to translate, measure, and predict the complex, the future, and even the incommensurable. They achieved historical success, although orthopedically framing the real in reality; after all, they had at hand some certainties and the notion that the gaps in knowledge had already been identified.

Still, the paper's objective is precisely to distinguish itself from this mold: it does not propose a total theory, but alternative modes of understanding, respecting the complexity of the objects (hence there is not one health ob- 
ject, but various objects, shaped by the respective disciplinary perspectives) and the plurality of this scientific task with a problem which is by definition interdisciplinary.

The author courageously proposes to tackle other powerful obstacles that resist attempts at a General Theory. The basic dimension of any theory, the concept, reveals the challenge of preserving its totality and polysemy, meanwhile being "objectifying". It becomes necessary to discern in the word health what is defined as concept, object, object-model, and field, both with regard to the heuristic aspect and the socio-cultural practices imbedded in these definitions (which are not restricted to $\mathrm{SmpH}$ but connect to a sociology of knowledge).

Some doubts remain as to the intents and their mode of presentation/organization. A General Theory is proposed in which each field of knowledge plays a role, contributing with certain operators. Adhered to each other within this theoretical system, which is understood as open, would such distinct epistemic traditions be comfortable? Would the "descriptors" be the possibility of objectivity capable of equalizing or assuaging such radical differences as well as promoting a trans- or interdisciplinary dialogue? Naturally any theory must "semantically discipline" the words and concepts it employs (Passeron, 1995). But how does one avoid transforming such a proposition into the grammar of a formal system? How does one resist succumbing to the clutches of structuralist logic? Thinking out loud, how does one preserve the poiesis, so dear to the complex thinking we claim for the health field, if one implicitly determines disciplinary roles a priori?

Given the limited space for debate, I wish to conclude by saying how happy I am to be able to initiate a dense debate, made possible by such a challenging text by Almeida Filho.

\section{Acknowledgments}

My thanks to Eduardo Alves Mendonça with whom I had the good fortune of discussing this review.

ALMEIDA FILHO, N., 2000. Qual o sentido do termo saúde? Cadernos deSaúdePública, 16:300-301.

PASSERON, J. C., 1995. O Raciocínio Sociológi co. O Espaço Não-Popperiano do Raciocínio Natural. Petrópolis: Vozes.

ROSENFELD, A., 1985. Texto/Contexto. São Paulo: Perspectiva
Rita Barradas

Barata

Departamento de

Medicina Social,

Faculdade de Ciências

Médicas, Santa Casa

de São Paulo,

São Paulo, Brasil.
In For a General Theory of Health: Preliminary Epistemological and Anthropological Notes, Naomar Almeida Filho proposes an entire research program that could result in the formuIation of a General Theory of Health.

Almeida Filho's article provides a careful review of production concerning the concepts and analytical categories proposed by different authors for an understanding of the health-disease processes, critically highlighting the limitation of models that have focused primarily on disease rather than health. Faced with this reiterative observation concerning the contributions of medical sociology, anthropology, and epistemology, we must ask the reason for such a sharp detour? Where precisely lies the impossibility of conceiving of health? One hypothesis, based on the contributions of Canguilhem and Agnes Heller, suggests searching the theories of needs for a possible explanation. Disease, as a concrete need objectified by individuals, necessarily appears as the object of reflection and action. Canguilhem calls attention to the existential fact that the suffering derived from diseases historically precedes the theoretical elaboration of diseases, thus giving precedence to what is experienced or "lived" as compared to what is reflected upon. Meanwhile, health is a utopia, a radical need in the sense used by Agnes Heller. In practice, thelimits of capitalist social organization made health needs impossible (and thus radical) for significant portions of the population. To what extent might this utopian nature of health have functioned as an epistemological obstacle to the formulation of a positive theory?

Returning to the beginning of the article, there are several remarks to be made to help expand the research program proposed therein.

Beginning with the contributions of medical sociology, I consider two aspects fundamental. The author emphasizes the predominantly biological reference in the approaches he analyzes. Still, more than the biological aspects, what appears to be at stake is the exclusively functionalist approach present in all the contributions and the fact that the analyses are limited to the individual, the hypothetical subject of the diseases, illnesses, sicknesses, etc. None of these contributions succeeds in conceiving of disease as a social and historical phenomenon with a collective dimension. In addition, the abstract systemic conception prevents the identification of different hierarchical levels among the phenomena. Hence the emphasis on the biological per se does not ex- 
plain the insufficiency of these approaches, although it has certainly contributed in the sense that the "negation of the biological" has appeared as an alternative for the construction of more appropriate theories in the anthropological watershed.

Furthermore, the author limits himself to analyzing functionalist contributions from medical sociology. The absence of representatives of other currents of thought like Siegerist, Pollack, and Juan Cesar Garcia further accents the critical analysis presented by the author, in the sense of the theoretical priority ascribed to disease, to the detriment of health. I do not mean to suggest that such authors have solved the problem presented here, but their contributions could be as useful to the undertaking as those of the functionalist sociologists. Such recourse to their work could allow for the incorporation of elements from medical sociology into the more promising contributions of both medical anthropology and epistemology.

In this sense the analytical scheme of Bibeau and Corin appears as a truly social formulation among those analyzed by the author, recovering the historical, social, and collective dimensions of the health-disease process, although it continues to concede greater relevance to the disease pole. Nevertheless, it would be worthwhile to ask whether this development is sufficient to consider it an adequate descriptor for the category of social health proposed by the author. Is the attempt at "closing" the framework not too hasty, given the precarious state of the reflections?

The contributions contained in Juan Samaja's creative reflection allow one to glimpse the possibility of overcoming many of the antinomies that have marked the health field. The theory of adaptive complex systems doubtless furn ishes a matrix to conceive of links between the biological/natural/historical/social; to more consistently elaborate the relations of determination and mediation between the different hierarchical levels in the constitution of re ality; to overcome the subjectivization/ objectivization dichotomy.

The scheme proposed by Almeida Filho in Figure 1 can serve as a map to begin the march in this research program, but along the road there will most certainly be a series of detours and sidesteps that will not make the path easier, but which may lead us to discover a more beautiful landscape.
Madel T. Luz

Instituto de Medicina Social, Universidade do Estado do Rio de Janeiro, Rio deJaneiro, Brasil.
My first comment is how current, relevant, and broad is the theme discussed by the author: the absence of a General Theory of Health in this interdisciplinary field of scientific production and intervention which until recently was called Social Medicine or Public Health, and which we now quite significantly refer to as Collective Health. One should also emphasize, at least in the conceptual terms in which the author situates his analysis, how unique his treatment of the topic is, as far as I know, especially in its original area, that of Epidemiology.

The second comment is that the theoretical "vacuity" referring to a positivity of heal th is present as demonstrated by Almeida Filho, not only in Epidemiology, the object of a previous study, complementary to this article, but also in the very field of human sciences focusing on the health-disease process in society and culture. Utilizing the basic categories present in this field (disease-illness-sickness) and related ones, conducting what he terms a semeiologic analysis, the author develops an extensive, intense, and erudite discussion with the main Anglo-American schools of thought in the fields of medical sociology and anthropology, subsequently delving into the main lines of contemporary epistemology.

As a third comment, I wish to emphasize that this conceptual and theoretical "void" is linked primarily to the predominance of the biomedical frame of reference in the social sciences (as the author demonstrates) vis-à-vis phenomena related to discomfort, suffering, and the loss of health and life by individuals, groups, and communities. What predominates in this frame of reference are categories that objectify pathology, disease, infirmity, as well as pairs of opposites such as normality/ abnormality, ability/disability, etc.

But the predominance of such categories is also presented (and here I begin my fourth comment) in culture and in basic social relations as a whole in contemporary society, becoming, for the subject, a storehouse of meanings in relation to the aforementioned phenomena.

Hence, the "objectivity" of such phenomena also becomes "subjectivity": the various subjects come to perceive and feel the loss (or the preservation) of their vitality "by the books", i.e., as established in normative terms by society and its institutions. The establishment of meanings in the scientific disciplines, whether from the biomedical or social field, is not disconnected from the historical development of 
modern society (quite to the contrary), from the establishment of institutionally "valid" meanings for the subject.

Parsonian functionalist sociological thought was unsurpassed in perceiving and giving form to this imbrication between vital order and institutional order in modern societies. It was no coincidence that the key category in Parson's thinking was that of social order, allied with the central concept of social system. However, this imbrication has affected social thought since the 19th century and is at the central constitutive thrust of the human sciences, as highlighted by Foucault in his Les Mots et les Choses, and can be flagrant in certain aspects of the work of Durkheim, of whom Parsons is a professed disciple.

The issue of social order (and hence that of deviation) identified with the polarity of social normality/disorder (or disturbance), and the latter indirectly with the life/ death polarity is a key point in the identification of sickness/ disease with vital disorder and of the latter with the indirect identification with the polarity order/normality, and disorder/deviation/disease in social thought. This set of identifications is al ready present in Comte, is assumed by Durkheim, and is transmitted in terms of a theoretical lineage to functionalist thought.

From my point of view the central issue in this set of identifications which "expels" from its theoretical nucleus such positivities as health, life, or vitality is the institutional issue, or more explicitly, the issue of institutional order in which is immersed the thought of both disciplinary fields (biomedical and social). Although the effort at grasping "subjective meanings" - or those linked to subjectivity in relation to phenomena ranging from sickness to death, or from recovery to cure - seeks a place in some phenomenological or vital ist formulations, the issue of order and deviation (and its necessary discipline) remains at the epistemological core of grasping these phenomena in the modern episteme, as demonstrated by Foucault. In this case, how does one secure the theoretical positivity of health, the author's great quest in the article at hand, through the idea of a unified theory of health?

From my point of view, theoretically securing a positive conceptualization of health assumes the epistemological and institutional deconstruction of the disease-illness-sickness order, i.e., in the final analysis that of the medical order.

French socio-anthropology (Dupuy-Karsenty, Boltansky, Herzlich, and Pierret, among others) has worked extensively in this direction in

the last thirty years. To be sure, it was not the object of the author's analysis, but it provides an important contribution in the sense of considering this necessary "deconstruction". On the other hand, Bourdieu's sociological thought offers interesting theoretical clues with the categories of field, habitus, and practice, in the sense of considering the origin of the theoretical void on health in the biomedical and social fields.

Finally, as a fifth comment, by way of posing a question, I wish to address the proposal of a unified theory of health. First: is it possible? General theories assume solidly established disciplinary fields, with unquestionable "root" concepts (although discussed in terms of their content or interpretation), which is certainly not the case of collective health.

Second, is it desirable? In the life sciences or social sciences, when a unified theory has been proposed, it has traversed biology as the unifying basis, which ends up incorporating a far-from-desirable set of deterministic and valuative propositions. I believe that in this case it is better to firmly prioritize basic concepts providing a positive basis for the health issue, to base it on a set of complementary theories that the functionalist Merton (Social Theory and Social Structure) called Theories of the Middle Range. Perhaps it might be a matter of conceiving a "grand theory" in collective health as a theoretical finishing line and not as a point of departure.

Jurandir Freire Costa

Insti tuto de Medicina Social, Universidade do Estado do Rio de Janeiro, Rio de Janeiro, Brasil.
The article by Naomar Almeida Filho confirms what one expects of him. It is rigorous, clear, informative, intelligent, and open to reformulation. It is not easy to outline what might be an all-encompassing theory of health. However, his attempt was successful. Hence the idea of a debate is welcome and timely, and above all pays tribute to the author's effort.

Since the topic is quite lengthy, I will restrict myself to approaching it from a very limited angle, that of the concepts related to the field. I wish to raise an issue, that of cognitive models, in order to hear his opinion.

I believe that the attempt to reconcile the various descriptions of the terms disease, disorder, illness, sickness, and malady is difficult and extremely complicated. Either one leaves 
out important aspects of the problem or one raises the all-encompassing model to such a level of abstraction that the formal presentation becomes acceptable, but debilitated in its practical effects. By practical effects I mean more or less clear rules, indicating how to conduct research, evaluate results, deal with discussion of the field, etc.

I thus propose renouncing the intention to construct a meta-theory of health in favor of prompt descriptions, subject to revision and further in-depth development. From this perspective, I believe that we might derive theoretical and practical benefit from dividing the health field into two sets, that of physicalist descriptions and that of mentalist descriptions. In the former, we would classify facts postulated as "causally independent" of linguistic meaning and amenable to being approached by quantitative methods, i.e., experimental methods involving control and prediction. This set would include the traditional problems of biological medicine at all levels of complexity. In the second we would classify the facts that were "causally dependent on linguistic meanings", i.e., all of the "qualitative", mentally phenomenic aspects of the health experience. This set would include the facts belonging to the domains of philosophy, anthropology, sociology, history, genealogy, psychology, etc.

The advantage of this model would be to simplify possible research scripts without requiring researchers to undergo the effort of reconciling investigations from very different areas of knowledge. Under the current state of health research, it is extremely difficult to ask experts to have a command over such highly diverse areas. The literature in each field is so extensive that very few are willing or prepared to attempt conciliatory schemata among theories originating from realms of investigation that are so far apart from each other.

The validity of specific investigations would be determined by the canons proper to each area, and the legitimacy of the scientific contests in each of them would be evaluated according to independent ethical criteria. Such criteria would be subject to debate among the researchers and community of citizens interested in the subject. Nevertheless, I suggest that a general principle be adopted, more or less tacit in medical deontology, as the point of departure, namely "minimum suffering with maximum autonomy". The controversies concerning the meaning of "suffering" or "autonomy" would be the object of empirical discussions or epistemological or linguistic clarification. Based on such a principle, we could judge

at what moment a given discipline was extrapolating its own field in an ethically legitimate way, which would require a description of the fact criticized according to another vocabulary or terminology.

To grant theoretical autonomy to the research sets means to respect what has al ready been done, taking better advantage of each one's critical potential. Thus, all discussion of the "qual ity of experience" of health, sickness, disease, illness, malady, normality, anomaly, etc. could be challenged, adjusted, corrected, improved, denied, etc., according to physicalist constructions and all nomological description of the same problems would be subject to debate according to the forms of knowledge that seek to offer empirical hypotheses concerning acquired beliefs related to the various "meanings" of terms like health, si ckness, suffering, autonomy, etc. The difference between the paradigms would be respected without our necessarily having to understand "incommensurability" as a synonym for "untranslatability".

This is the issue in broad terms. If Almeida Filho finds it interesting, it would be extremely helpful to hear what he has to say.

Jaime Breilh

Centro de Estudios y Asesoría en Salud, Quito, Ecuador 
ry of health, precisely at a time characterized by a widespread questioning of "general scientific frameworks" and "meta-accounts" encompassing broad interpretations in fields of knowledge. And our answer is emphatically affirmative. Based on a profound and well-informed essay, Naomar Almeida Filho invites us into a timely and necessary debate. $\mathrm{H}$ is article demonstrates not only his own maturity as an investigator and epistemologist in heal th, but also that of the entire Latin American Social Medicine movement, which has provided decisive contributions from various countries.

Beyond the possibility of adding new facets to Almeida Filho's analysis (and we are familiar with several such sources from Latin America that would doubtless enrich the purposive conclusion to his paper), we must acknowledge how correct he was in fueling the critical flame in the much-needed debate over a general theory of health.

The reading Almeida Filho provides us with on the problem, and that leads him to conclude with his proposal of "modes of heal th", begins and continues with a line of analysis strongly linked to the contributions from European epistemology, and therein lies both the strength and importance of his contribution, as well as its limits. The objective of my brief commentary is to outline this strength, as well as the limits, and highlight the need to incorporate other perspectives.

The importance of Almeida Filho's contribution can be grasped by retracing the logical cycle he follows, woven around a critical reading of various contributions from sociology, anthropology, and epistemology. The entire first section of his essay is devoted to displaying the inability of psycho-biological approaches to fully deal with the health object, due to their focus on individual disease processes and their negative view of health as the absence of disease, i.e., proposals constituted through functionalist sociology that distinguished between physical and perceived sickness with the goal of explaining sickness as the impossibility of performing personal and organic functions. $\mathrm{He}$ also questions the concepts provided by phenomenology, centered on the restrictive notion of health as the absence of perceived sickness. Hence the author's quest having turned towards the contributions of psycho-cultural anthropology, emphasizing the role of culture in constructing the notion of "sickness" (enfermedad) - through a shared language and the creation of "health/sickness/ care" cultural complexes under the formula sickness =disease + illness (Kleinman), the study of the forms of as- cribing meaning and the formation of semantic networks (Good \& Good), or even the incorporation of social and power relations as determinants of the interpretative models for sickness as an attempt to surmount the micro-social (Young). Such approaches were also centered on the notion of sickness and curative practices. And towards the end of his critical inventory, Almeida Filho reviews the semeioIogic approaches that attempted to overcome the micro-social limits of previous lines of analysis, incorporating the analysis of the relationship between semantic structures and hegemonic and power structures (Good), as well as the variants challenging excessive particular emphasis, proposing the need for a macro-social historical approach centered on the observation of structuring collective conditions and conditioning experiences that combine in systems of "signs, meanings, and practices in health" that do not obey Western medical logic and that appear as non-stable and diffuse prototypes (Bibeau \& Corin). Almeida Filho recognizes that this latter view not only continues to be framed in the notion of sickness, but that it expresses a certain anti-naturalism that leaves aside the problem's biological material elements.

At this point our author launches into the quest for a veritable epistemology of health through an analysis of Georges Canguilhem's thought. He analyzes the French epistemologist's proposals of considering normality as a life norm that incorporates the healthy and the pathological, whereby health is not considered simply the obedience to a norm or model, since disobedience and deviation are part of health, and approaching the discussion of this free and unconditional "philosophical health" that is forged in physicians' praxeological scenario with their patients and is also projected into a public health linked to the notions of utility, quality of life, and happiness, a process that is finally realized in the phenotype and is observable. Almeida Filho recognizes the importance of a Canguilhemian opening towards a new epistemology, yet criticizes the premise that this vision is linked fundamentally to the biological, despite recognizing "that health is not only life in thesilence of the organs... but also lifein thesilence of social relations" and that scientific health should assimilate aspects of subjective and philosophical individual health in such a way that it is not reduced to sickness and so-called "risks".

In short, through his epistemological tour, Almeida Filho has succeeded first of all in clarifying the inability of psycho-biological and 
psycho-cultural models to overcome the negative definitions and solve "Kant's problem" of this resi stance against conceptualizing heal th in and of itself, and secondly in retrieving the potential of Canguilhem's opening, but signaling its focus on the biological terrain, just as Foucault's explanation was oriented towards merely social and discursive explanations.

In the final, purposive section, Almeida FiIho turns to the contribution of Juan Samaja, with his idea of multiple determination with hierarchical interfaces, an important Latin American line of reflection that adds to other contributions that have opened the doors to an integral conceptualization.

Within these brief comments, we do not intend to develop a profound analysis of the "modes of health" proposals or its basis on the idea of hierarchical interfaces, since this merits elaboration that we are incorporating into other article. The point here is first to highlight the value of the pathway that Almeida Filho has called us to follow and the germinative potential of some of his ideas for epistemological work in the coming years. However, secondly, we are interested in identifying here some of the limitations of his approach, as well as an unresolved epistemological problem that is not visible in his analysis, despite its importance, namely, what he would refer to as resistance towards thecollective.

Epistemology and history teach us that in Science, the processes of conceptual cleansing proposed from an emancipatory perspective are closely linked to the need for practical advances in collectives that develop their process in the midst of hegemony, are full of intentionality and conditioned by the horizon of visibility and their social contextualization, a horizon that depends extensively on epistemic conditions - in the Foucaultian sense - as well as the practical articulations of the scientific. In this sense, we ask whether the only "point of departure" or take-off in the critical process is the inventory of contributions from European thought, or if there is not a need to think out our own model and orient our reflections beyond this single point of view, within an intercultural construction and the perspective of critical multiculturalism.

While the construction of a scientific discourse on health in general is an academic issue, it involves intellectual work and a practice that go beyond the limits of academe, but which are part of the construction of knowledge.

To orient the current work, we need to clarify its nature, content, and direction, and this is not possible. At least from a democratic and in- tegral perspective, this can only be done from the scientific community and based on a vision inspired exclusively by the cardinal problems and points of growth established by European epistemology, no matter how important the latter may be.

To establish what we are referring to when we speak of a general theory of health, i.e., what the difference is between a broad and innovative theory and a matrix, unilateral, and hegemonic account - and to analyze who we are calling on for such an undertaking, it is necessary to call other societal perspectives into the debate, and this is not only a logistic, practical problem, but also a theoretical one. Furthermore, from a praxeological focus, a general theory not only defines the object of transformation in a scientific field, but also the subject of said transformation, and the two go hand in hand, since they are interdependent elements of knowledge. Stated differently, we presuppose here that if a theory cannot be reduced to a reflection induced in thought, nor can it be a simple deduction of real ity based on a rational model, then a general theory of health should encompass the historical subjects mobilized around the object as a field of action in this case the field of health - both as the broadest of processes that constitute its complex object and with its hierarchical domains, with its macro-micro and social-biological articulations

As Latour (1999) would explain metaphorically, the idea of a separation between the world (outside) and the mind (inside) that is present in the form of both positivist objectivism and that of rationalism and phenomenology allowed for the creation of the notion of an "objective world", unreachable for the common people below; and this false disjunction made it possible to impose the power of cold, scientific reason, outside of a human collective stigmatized as an irrational mass.

The construction of a new basis for a general theory of health that Almeida Filho calls us to reflect on cannot be achieved through this open or disguised polarization between the "subject", the "objective world", and the "mass", but from a praxeological view that dissolves such a polarity and recovers the human side of scientific practice and its profound relations with the collective. As expressed by the Scientific Institute of Indigenous Cultures of the Confederation of Indians of Ecuador, it is part of the struggle for "diversity with equity... within a context of political democracy, social justice, and economic equality" (ICCI, 2001), the urgency to construct life and health as an an- 
tithesis, which are expressed outside the world of academe and form the best interpelation concerning the meaning of science.

$\mathrm{ICCl}$ (Instituto Científico de Culturas Indígenas), 2001. Editorial. Boletín ICCI-RIMAI, 24.

LATOUR, B., 1999. Pandora's Hope: Essays on the Reality of Science Studies. Cambridge: Harvard University Press.

Gilles Bibeau

Département d'Anthropologie Université de Montréal, Montréal, Canada.
In defense of a creolized grammar of the health-disease complex

"The cul ture of any soci ety at any time is more like the debris, or fall-out, of past ideological systems, than it is itself a system, a coherent whole. Coherent wholes may exist (but these tend to be lodged in individual heads, sometimes in those of obsessives and paranoiacs), but human social groups tend to find their openness to the future in the variety of their metaphors for what may be the good life and in the context of their paradigms" (Victor Turner, 1974:14).

The perspective I favor in my response to Professor Naomar Almeida Filho borrows first from work in the anthropology of science produced by Latour (1999) and Hacking (1999) and second from my own experience as a researcher in the area of medical anthropology, a sub-discipline that emerged from studies conducted primarily in non-Western societies during the colonial era. In those days anthropologists were busy portraying particular beliefs (witchcraft, sorcery, magic) invented by people to explain misfortunes, disasters, and diseases, and describing therapeutic rituals (spirit possession, magical devices, anti-sorcery ceremonies) that healers applied to treat particular episodes of the disease-illness-sickness complex. Few anthropologists have shown a keen interest in developing an anthropology of health as a counterweight to the "disease perspective" canonized by classical medical anthropology. Only recently have anthropologists begun to consider the issue of health and well-being as a topic which deserves full attention. The essay by Professor de Almeida Filho is a timely contribution from which medical anthropologists should greatly benefit.

I begin by briefly stating my stance as a medical anthropologist. In my view, humans in all societies are confronted with the same fundamental "existential problems" and "anxi eties", like the awareness of the inevitability of death (mortuary rituals and after-death cults to the departed), the origins of evil, suffering, and disease (magic rituals, religious ceremonies), and difficulty in maintaining harmony, cooperation, and well-being. Human societies responded to these challenges by combining two series of representations, ideas, and practices: (a) a symbolic idiom built around basic mimetic (metaphorical and metonymic) processes which helped them assign meaning to their afflictions and (b) an empirically-oriented attitude that eventual ly gave birth to what we now call science. Ritual healing practices have developed at the interface between the symbolic idiom and the pragmatic effort to tame the "bad" via the use of plants, curative interventions, and other reparative techniques. Throughout the millennia, the search for meaning and the drive for knowledge have served as points of departure for further theoretical elaborations in the various cultures which all ended up inventing their own therapeutic systems, among which one finds Western medicine.

I agree with philosophers and historians of science who have amply demonstrated in recent decades that scientific facts, theories, and concepts are value-laden and that medical, psychological, and socio-anthropological knowledge on either health or disease is culturally and historically constructed. Experts in the ethnography of science have shown that all forms of knowledge are largely context-dependent products rather than transcendent realities, and that the prevalent Western literature in contemporary biology, medicine, psychiatry, and health-related social sciences tend both to bring particular theoretical frameworks, categories, and models to the forefront and to suppress or silence alternative ways to assess, interpret, name, and theorize certain areas such as the health/ well-being complex. Meanwhile, critical social scientists insist that the production of knowledge is never neutral, that there is no such thing as a "mere fact" or an evidencebased theory, and that scholars, intellectuals, and theory-builders themselves are inevitably linked to a particular ideology or set of beliefs.

By combining a socio-anthropological dimension with linguistic, semantic, and epistemological considerations, Professor Almeida Filho has established a solid foundation for delineating a theory of health which incorporates all major elements put at work in the double strategy, namely the beliefs systems and the scientific response to which humans resort wherever and whenever they face misfortune, disease, and other sorts of problems. I enthusi- 
astically support the line of argument proposed by Professor Almeida Filho in his challenging essay. To organize my own thinking about what a theory of health is, I found it useful to explore five areas: the "perfect health" ideology; biology as a historical and interpersonal script; humans as producers of languages and idioms of health-distress; the life of people in multiple worlds; and local epistemologies. I feel that all these five domains should be considered as necessary and complementary sources in the theorization of the heal th domain. I conclude my own questioning by asking whether there is room for theory in modern science. The path I decided to take leads exactly where Professor Almeida Filho was heading: concentrating on health rather than disease and introducing local epistemologies in the construction of a general theory of health.

The quest for "perfect health"

The "well-being complex" has been installed as a key symbol in Western culture, particularly in countries of the Northern hemisphere: techniques of all sorts and a rhetoric of persuasion (e.g., from body massage to religious enrollment) are currently used to discipline the body and regulate individual life styles. In certain contexts, the therapist-patient relationship has also been transformed into a continuous and long-term relationship for body management (clinical surveillance or regular check-ups to verify the results of treatment), giving rise to a growing "care industry" which has colonized the heal th domain by medicalizing social and psychological conditions which have to do with the very fact that a person exists. One can easily find multiple examples in both industrial nations and the developing world of medical technologies aimed at controlling deviant behavior (hyperactive children, drug addiction, etc.), as well as plagues, diseases, and even natural life cycle events (childbirth, menopause, etc.).

Such heavy reliance on healing techniques for the body and mind reflects one of the central concerns of our era: the achievement of a "perfect health" status. The pharmaceutical industry spends billions on research into treatments for such problems as obesity and overweight, baldness, wrinkles, acne, depression, and impotence, leading to a "life style drug market" that induces people to fantasize about the perfect body, mood, and mind. All this reinforces people's dependence on "experts" of various vintages and on the multiplication of medical techniques geared to reestablish equilibrium and repair the body-mind complex.
In the past, medicine's role was to heal the human body from sickness. In our age, medical technologies aim to do much more: modern medicine is, intentionally, total recovery, organ transplants, cosmetics, and self-help rehabilitation. While modern medical technologies can effectively cure the sick body, it also claims to alter the body and mind in such ways as to improve performance, preserve youth, achieve immortality, reduce or eliminate gender differentials, and eventually reach the utopia of "perfect heal th". Based on these premises, prevention has become a massive technological enterprise, often involving sophisticated and costly genetic prediction procedures, and reinforcing dependence on scientific technologies, but also creating more ethical dilemmas and growing contradictions.

Biology as a historical and interpersonal script

We have entered an era dominated by a new biology that links the brain-mind complex to environment and history, both at collective and individual levels. The schism introduced in modern biology by Descartes' dualism of mind and brain has been thrown to the wind: new ways are emerging to perceive the body, the mind, the emotions, and the health-disease complex. The mechanistic philosophy which used to see the body as a machine is visibly dead (or dying): contemporary (neuro)biology is based on the indissoluble relationship between the person's life experience and the modeling of his/her biological memory, the historical shaping of individual neurological architecture, the coding of neural networks along with one's personal history, and the biopsycho-social dynamics of higher consciousness. Biology is thus seen as dynamic, interpersonal, historical, and evolutionary. Individual experiences constantly inform the biological networks and provoke rapid and ever-changing patterns in the neurological codes. Individual histories shape brain and mind simultaneously; the brain and mind are indissolubly linked to each another and to the person's actual history.

Neuroscientists, evolutionary psychologists, and biological anthropologists generally agree that individual neurological maps are both historically and environmentally produced. Neural codes are formed through: "une mise en correspondance entre, d'une part, un état dechoses extérieur, un objet, une situation, et d'autre part une organisation neuronale et l'état d'activitéqui l'investit"' (Changeux, 1998: 113). Thus, differences in the epigenetic devel- 
opment of persons (particularly in the family environment) contribute to differences in the organization of each individual's biological architecture. It is true that the more we know about the interactions between genetic and non-genetic factors, the more complicated these interactions appear to be: the ways in which "causation" functions are often far from self-evident, and a number of feedback loops, both positive and negative, are constantly at work. The accepted explanation of "causation" from genes to culture, as from genes to any other human phenomenon, is neither exclusively hereditary nor exclusively environmental: it is interaction between the two. This is also common knowledge among people in most cultures around the world.

Nevertheless, the "historically-grounded biological model" has weaknesses: it discards what people do with what they produce, the meanings they attach to their local productions, and the experiences they construct. It is not surprising that scholars who examine human phenomena from the perspective of persons consider the "historical script" in biology to be reductionist, animal-driven, and still excessively deterministic, despite its effort to overcome past dualisms, like that proposed by Descartes. Undoubtedly there is still significant misunderstanding between historically and culturally minded biologists and social scientists, but much has been done to narrow gaps from the past. It is now possible to move beyond the past opposition to establish solid, bal anced cooperation between the socio-cultural and biodynamic paradigms, in a partnership in which both perspectives are equally valued and respected. Professor Almei da Filho adds to this line of thought a strong interest in the meaning-based and experiential dimension of the health-disease complex.

Humans as producers of languages and idioms of health-distress

Language is the function that characterizes the species (Homo sapiens sapiens) as distinct from precursor primate systems of communication: it is emblematic of a universally structured human mind, the same in all places and times. Chomsky has demonstrated that all human languages share certain universal features, both at the syntactic level of grammatical categories and at the phonological level of sounds. He argues that there is a Universal Grammar which is linked to the fact that humans are equipped with the same innately programmed capacity for language, representation, and sym- bolization. Like the complexity of language itself, the capacity to represent (signifier-signified) and to symbolize (minimally the mimetic faculty) is seen as being intrinsic to the neurological organization of the brain and to the functioning of the mind; in paral lel, representational and symbolic capabilities are said to be linked to the linguistic ability that defines human beings. One may draw two conclusions from these observations: (a) probably beyond all these phenomena, there exists a metastructure (consciousness?) which is thoroughly organized in the form of a language; (b) all other physical, mental, and symbolic capacities are also constituted as built-in programs and may thus be seen as translating this same linguistically-shaped meta-structure.

Human beings build diverse and sophisticated cultures. Contrary to non-human primates, human beings are not only equipped to produce language: they actually speak one (or many) language(s) and assign meanings, generating multiple narratives and stories on the basis of the grammar(s) they master. In addition to languages, human groups invent myths and cosmologies which provide blueprints to interpret the world in which they live, ideologies, belief systems, and moral norms which tend to vary (probably around a universal core) from society to society as well as particular social rules (family patterns, inter-group relations) which serve as a foundation for constructing the ways "to be a person" in a given society. All these ingredients compose what anthropologists refer to as a "culture". Our modernity is constituted, as any other culture, as the ensemble of narratives, stories, and experiences that people generate on the basis of the values, norms, symbols, and myths shaping the contemporary world.

In their study of narratives and experiences produced by individuals, many social scientists in recent years have adopted an interpretive and phenomenological stance which borrows much from semeiology, literary criticism, and European existential phenomenology. Merleau-Ponty was one of the leaders in the postwar industrial world of a movement to renew philosophy - initiated by Husserl with phenomenology - that involved a new relationship between body and mind, a topic that had remained unchallenged since Descartes. Merleau-Ponty's phenomenology does not envision the body-mind as a duality, nor as a dichotomy, but rather as the translation (expression) of a "double nature": corporeal ity returns here in the form of a vehicle, leaving room for meaningful experiences that persons are able 
both to live and to put into words. Discourses, narratives, and complaints that persons phrase to express their emotions are inevitably shaped by the idioms provided by the culture(s) to which they belong.

For several decades social scientists have argued against all sorts of reductionist theories that attempt to model the study of persons and human cultures (including human health) on an animal model. They have reminded their biomedical colleagues that the problem of signification (meaning) is tied to human beings' self-definition and that the practice of human sciences thus requires the inclusion of semeiology and hermeneutics. Human beings are ontological beings who cannot avoid interpreting themselves, others, and the world. "Human beings are self-interpreting animals", anthropologists write repeatedly, echoing a central theme in contemporary social sciences.

I firmly believe it is important, as Professor Almeida Filho does in a convincing way, to examine specific interrelations between collective meaning systems, local idioms of healthdistress, and individual discourses of well-being and pain, that is, to know how people experience and express emotions and how they connect somatic symptoms with their inner psychological states. This requires a critical review of past and current hypotheses of how symptoms are produced, constructed, and experienced by different peoples or cultures under varying social, material, political, and psychological conditions.

To date, research on idioms of health-distress has emphasized the ways such idioms are shaped by cultural taxonomies, explanatory models, and popular semeiologies, at times neglecting the social context in which the person lives and the person's spatial position - in many cases - at the boundaries between multiple cultural worlds. Anthropologically-minded psychiatrists and psychologists also favor elements within a person that can be connected to categories such as "symptom schemes", "illness schemes", and "idioms of distress".

Besides meaning, two other important notions, namely narrativization and experience, are attached to the perspective opened by the phenomenological and interpretive turn of medical social sciences. It is not enough to say that people act towards things in at least partial congruence with the meanings these things hold for them. People also produce discourses, commentaries, and narratives in which they tell, via complex rhetorical strategies, the meanings associated with their experiences and behaviors. Their idioms of health-distress and their health-illness explanatory models and schemes are also largely dependent on their systems of meaning. To be properly understood, the various narratives and idioms have to be inserted within a series of other discourses and ultimately placed in the larger context of the culture which supports these texts. We must take into account the fact that human speakers incorporate cultural presuppositions into their narratives, that the blank spaces of discourses are loaded with meanings, and that any reading limited to the surface runs the risk of missing the cultural dimension. The stress put on narrativization is sometimes so strong in contemporary medical social sciences that some scholars, particularly medical anthropologists, have come to see culture as nothing more than a mega-text.

\section{People today stand on the boundaries of many worlds}

In almost all modern countries, one finds the coexistence of multiple languages, religions, and cultures. The dialectic notions of center and periphery, inclusion and exclusion, majority and minority are commonly used by social scientists to study the dynamics of cultural power, cultural pluralism, hegemony and dominance, control and submission, and the relations that either oppose or link the various social groups in a given society. Most people today live on the boundaries between groups and define themselves as persons with multiple affiliations. It appears particularly urgent to tackle the challenges created by the impact of such pluralistic societies (many religions, languages, and cultures) on both individuals and families. Cognitive maps, values, and systems of meaning are reorganized to fit the plural ist context, with vacuums and cracks in their midst. Recent research frameworks take into account the contradictions and tensions emerging from the pluralistic situations in which individuals and groups live. Creolized versions of cultural systems have emerged on all continents, and citizens of most countries are therefore torn between multiple parallel attachments, while people everywhere are trapped between fidelity to one's cultural identity and the need to assume a more flexible pluralist frame of reference (Bibeau, 1997).

The ethnic, linguistic, religious, and cultural pluralism which was already present in the vast majority of countries is greatly accelerated by migration, displacement, and refugee movements across national borders and by the fact that countries are increasingly permeable to 
influences from abroad. In most countries, people are forced to confront more and more ambiguity, with multiple group affiliations and hybrid identification models at the edges of their cultural worlds. The dominant challenge in all pluralist societies is to build collective cultural reference systems that combine the local with the global and community-grounded values with a common sense of belonging.

In their comments on the interpretive turn that human sciences have taken since the mid1970s, Rabinow \& Sullivan (1985:35) wrote: "Common meanings arethe basis of community. Inter-subjective meaning gives a people a common language to talk about social reality and a common understanding of certain norms, but only with common meanings does this common reference world contain significant common actions, cel ebrations, and feelings. These are objects in the world that everybody shares. This is what makes community". Inter-subjective meanings are not only located in the minds of people, but are also incorporated and expressed in their collective practices and constituted as social actions. Only a direct experience of the world of others provides a sense of pre-comprehension about the meanings people attach to their behaviors and actions. This implies that researchers must become familiar with the world of others (natural settings) and experience it at least partially if they want to be able to grasp something of the world in which people live. All this becomes more complex when people start living in multiple parallel worlds as in contemporary societies.

Local epistemologies as a source for theorizing

We know that indicators (markers, signs, symptoms) used by people to identify actual health problems as well as lay explanatory systems do not exist as explicitly conceptualized bodies of knowledge that can be easily reconstituted and transformed into a sort of textbook of "popular pathology". Such knowledge is rather enacted and manifested in the actual behaviors of people (patients, families, community groups) when they are faced with concrete cases. I feel that any exploration into theory in the healthdisease complex must consider at least the following three series of data: (a) the local representations, ideas and practices developed to see the world, to be a person, to conduct a valuable life, to produce well-being, to organizetime and space, and to relate to material progress; (b) the indigenous values rel ated to the bodymind, to the health-disease complex and to the spiritual aspects of human life; and (c) the knowledge regarding the natural, physical, and social as well as psychological, spiritual, and cultural dimensions of the world in which individuals and groups live. Professor Almeida Filho's theorization of health and disease is precisely based on a comprehensive approach that includes social and cultural traditions as well as local systems of knowledge.

Ordinary people have learned that responses provided by health professionals and "experts" cannot suffice to alleviate their problems and that sustainable solutions require alliances between locally-based interventions and professional actions and, more globally, a true integration between the values and practices of people and formal professional practices. Locally produced, collective healing responses have a greater chance of matching the needs and actual problems as experienced by individuals and groups. As a note of caution, however, while I acknowledge the relevance of such community-based lay knowledge, I should also recognize its own constraints and limitations. Professor Almei da Filho is, I think, on the right track when he looks for an implicit theory in the different systems of signs, meaning, and practices.

Is there any place for theory in modern science?

Professor Naomar Almeida Filho is aware, probably more than anyone else, that modernity is usually associated with secularization, the idea of progress, the dominion of facts, the systematization of knowledge in general, and the rise of "science". A strong reliance on science, (arti)facts, and data has been - and still is - a totem of the modern Western approach to the world. There is no doubt that the Brazilian professor fully agrees with Max Weber when he referred to the trajectory of modern thought as the "disenchantment of the world" and thus to its de-theorization. Despite such evidence, Professor Almeida Filho argues that science needs theory in order to be complete. The rise and dominance of new forms of science (biology, medicine, psychiatry, anthropology, psychology, and sociology) have actually led to the preeminence of certain conceptual models for the ways people's health, suffering, pain, and distress are commonly constructed by clinicians, medical experts, and social scientists. In this respect, contemporary biomedical science is responsible for the creation of taxonomies of disease that are assumed universal, value-free, and autonomous from history and culture. All this is clearly stated in Almeida Filho's essay. 
Professor Naomar Almeida Filho has also mapped, with an excellent knowledge of current debates, the new territory explored by historians, sociologists, and anthropologists who have argued that both the subjective experience and subsequent recognition, labeling, and interpretation of the health-distress-disease complex are socially and culturally produced (Bibeau, 1995, 1997; Bibeau \& Corin, 1994; Foucault, 1966; Good, 1994; Kleinman, 1988; Young, 1995). These researchers advanced the idea that representations, values, and concepts concerning health and disease are inevitably created within a context of multiple forms of knowledge which are as much grounded in local epistemologies as they are linked to the scholarly academic world. These forms of knowledge affect the ways by which the lifeworlds of persons are built and design the architecture of that fuzzy area covered by what social scientists name, with some hesitation, the health-disease-illness-sickness complex. In other words, following Hacking (1995), "styles of reasoning" are integral to both medical discourse and the culturally-framed ideas built around the health-disease complex. Anthropologists have also demonstrated that these "styles of reasoning" vary in important ways across disciplines in academia and according to different social and cultural settings.

Professor Naomar Almeida Filho has investigated, with great scrutiny, heuristic concepts such as "styles of reasoning”, "Iocal epistemologies", "systems of signs, meaning, and practices", and "transdisciplinarity", with the intent of formulating the groundwork for a general theory of (public) health. He has courageously navigated on troubled seas, on the ones traveled by medical sociologists and anthropologists who over the past three to four decades have emphasized the socio-cultural dimensions of the health-disease complex, and as well on other seas, even more dangerous, explored by the promoters of critical epistemology in contemporary social, cultural, and medical sciences. However, the time for celebrating the achievements of transdisciplinary collaboration has not yet come, contends Almeida Filho, particularly when one examines the paucity of theories developed around the "substance" of what is health. There is still much fragmentation in the production of knowledge, and theory-building is still a potential proposition, far from being implemented in reality, although biomedical and healthrelated social scientists have begun to provide new conceptual frameworks for assessing human phenomena, particularly phenomena associated with health and disease.
Professor Almeida Filho has argued that it is through the evaluation of frames, models, and practices commonly used in science (by biomedical and health-related social scientists) that we will eventually gain a better understanding of how suffering, distress, and pain are transformed into nosographic categories and eventually absorbed into the scientific domain. He also notes that it is essential to promote a greater heterogeneity of models, theories, and concepts as a counterweight to the increasing homogenization of disease-oriented knowledge and theory. The perspective that I have explored in my response calls on us all to seriously consider the way ordinary people construct their own models of health and disease The people I know all live on the boundaries of many worlds and construct their representations of the health-disease complex in reference to a creole grammar. Any theory of health and well-being should take full consideration of this fundamental fact. And I feel that anthropologist Victor Turner (1974:14) was correct when he wrote that "human social groups tend to find their openness to the future in the variety of their metaphors for what may be the good life and in the context of their paradigms". Theories are embedded in responses societies develop to produce "the good life".

BIBEAU, G., 1997 Cultural psychiatry in a creolizing world: Questions for a new research agenda. Transcultural Psychiatry, 34:9-41.

BIBEAU, G. \& CORIN, E., 1995. Beyond Textuality. Asceticism and Violence in Anthropological Interpre tation. Berlin: Mouton de Gruyter.

CHANGEUX, J.-P. \& RICOEUR, P., 1998. La Nature et la Règle. Ce qui nous fait Penser. Paris: Éditions Odile Jacob.

CORIN, E., 1994. The social and cultural matrix of health and disease. In: Why are Some People Healthy and Others Not? TheDeterminants of Heal th of Populations (R. G. Evans, M. L. Barer \&T. R. Marmot, ed.), pp. 93-132, New York: Aldine de Gruyter.

FOU CAULT, M., 1966. Les Mots et les Choses. Une archéol ogie des Sciences Humaines. Paris: Gallimard.

GOOD, B., 1994. Medicine, Rationality, and Experience. An Anthropological Perspective Cambridge: Cambridge University Press.

HACKING, I., 1999. The Social Construction of What? Cambridge: Harvard University Press.

KLEIN M AN, A., 1988. The IIIness Narratives. Suffering, Healing $\&$ the Human Condition. New York: Basic Books.

LATOUR, B., 1999. Pandora's Hope. Essays on the Reality of Science Studies. Cambridge: Harvard University Press.

RABIN OW, P. \& SULLIVAN, W. M., 1979. Interpretive Social Science. A Reader. Berkel ey/Los Angeles/ London: University of California Press.

YOUNG, A., 1995. The Harmony of Illusions. Inventing Post-Traumatic Stress Disorder. Princeton: Princeton University Press. 
O autor responde

The author replies

Naomar Al meida

Filho
Local epistemologies and general theory of health: a rebuttal

The commentary by Roberto Briceño-León shows profound skepticism as to the feasibility or even validity of a proposal to conceptually develop the health object in the direction of a General Theory of Health (One of the other commentaries defends a position similar to that of Briceño-León but includes a set of nonsystematic and impressionistic propositions on the health theme, without even referring to the content of the essay under debate. In said commentary, the use of concepts is quite idiosyncratic and disconnected from the theoretical schemata I have analyzed, thus hindering its incorporation into the present line of debate. I thus lack a basis for incorporating it into this rebuttal).

Before analyzing the content of BriceñoLeón's critique, I should point out some misunderstandings I find in this commentary: in my article, I did not appeal to the concept of sickness to define health, did not propose any definition of health, and did not state that health was something that is lost. Briceño-León purportedly agrees with Gadamer (1996) by taking health as a feeling, a living experience, an effect of subjectivity, an element of individual imagination. He contends that sickness constitutes a social construct, while health would be a construct "located in the shifting terrain of desire". I cannot agree with such a position. In preparing for this debate, I ended up overcoming that hint of doubt by reviewing and reaffirming the main argument in my text. In full agreement with Samaja (2000), I refer to the indication of plural, multifaceted, and multi-leveled nature of health, which can manifest itself in different hierarchical planes of complexity. Thus, Gadamer's proposition (and BriceñoLeón's "intellectual free ride") would only apply to the individual level, where unique, private, subjective - in a word, individual - space is realized.

I must also contest Briceño-León's verdict that "Health as a general theory does not exist [because] there are only historical claims". Two assertions result: first, that health is not justified as an object of science; second, that theories are not historical constructs. The epistemological principles that sustain this line of argument are incompatible with the dominant approaches in contemporary theory of knowledge. It is not the attributes of events or phenomena that determine the construction of the object-model but scientific praxis marked by the limits and barriers (conditioning factors) of concrete reality (Samaja, 1994). The theories, in turn, are essential tools in the process of constructing the object, always beginning as "historical claims" (or knowledge projects) and becoming both historical and formal constructs.

Luiz David Castiel states that the concept of risk is "conceptually frisky [undisciplined - T. $\mathrm{N}$.]", in the sense of displaying a certain mutant and imprecise nature. In epistemological terms, I do not agree. There are few objects of science with such a rigorous degree of formal elaboration as the object-model "risk" in the field of Epidemiology (Miettinen, 1985). As I had the opportunity to point out in A Clínica e a Epidemiologia (Almeida Filho, 1992), the term "risk" appears in epidemiological science (and also in Economics) as a theoretical concept, in Clinical Medicine as an operational notion, and in common social discourse as a praxeological notion or as "social perception". Castiel insists and asks: What cut-off point clearly defines which groups are actually at risk and which are not? How does one deal with the more vulnerable groups (by age, gender, ethnicity, etc.)? The answer to the first question is simple, at least in epidemiological terms: the threshold for ascribing the risk factor category is a relative risk of 1.0. For the second question, suffice it to apply the notion of "reference classes" (Boorse, 1977), evaluating normal functions not in relation to what is typical (or exceptional) for the species but for what is typical for the class origin of the subject or group at issue.

Responding directly to other pertinent questions by Castiel, I pointed out in the text cited above that the signifier most closely linked to the popular notion of risk is actually that of "danger". Giddens (1990) and Beck (1996), representatives of an important line of post-Marxist thought, propose that societies developed in a certain direction converge towards a "society of risk". I thus deem worthy of debate Castiel's proposition of employing the $\mathrm{SmpH}$ descriptor for risk also and not only for illness. Yet the only frame of reference for the risk concept that I recognize as scientifically based is still Epidemiology. Respecting the possibility and validity of approaching risk as a theme in 
the fields of sociology and anthropology, I prefer to restrict the range of application of concepts analyzed herein based on the position that precisely there lies its efficacy as a heuristic device.

I thank Castiel for enriching the current debate, commenting in depth on the topic of prototypes, clarifying its origin and conceptual insertion. However, I disagree on several points in this regard. Indeed, Lakoff (1993) does grant all the credit to Rosch and his school, but advances considerably in the formal consistency of the concept and its generalization to other themes beyond biology and the psychology of perception. Rosch's theory of prototypes cannot be "amenable to immediate understanding" by fuzzy logic, but Lakoff's theory of prototypes certainly will be, since the author himself so indicates based on an analysis of the insufficiency of classical logic vis-à-vis the conceptual requirements of ambiguous and imprecise objects. Castiel is right in pointing out that originally the theory of fuzzy systems did not mean any break with formal logic but rather an attempt at updating it in terms of categories of gradation. However, its subsequent development outside the technological field (in the narrow sense), principally in the application to analysis of cultural systems as proposed by Lakoff (1993), resulted in an effective alternative to classical logic and the theory of discrete sets derived from it.

In the field of heal th, there are practically no applications of the notion of prototypes, despite its undeniable proximity to the problem of superimposed diagnoses or co-morbidity, as highlighted by Mezzich \& Almeida Filho (1994), and to the issue of the fuzzy nature of definition for both exposure and risk in the epidemiological frame of reference (Costa-Capra, 1995). An interesting recent update on the subject was published by Sadegh-Zadeh (2000), emphasizing precisely the theoretical and practical uses of fuzzy logic in research on healthdisease.

Castiel, careful as he is (or obsessive, like all us proud children of science), should investigate the meaning of "obverse" to determine whether it is actually fitting to use such a category in the health object. First, I should say that it is a proposition by Parsons himself (1978), to whom the fair criticism should beaddressed. But since it is no longer fashionable to criticize Parsons for being Parsonian, I contend that it is a subtle and intelligent indication of the dialectic nature of the health-disease dyad. The Brazilian standard dictionary Aurélio is not exactly a philosophical source worthy of imme- diate credit; in addition, the reference to Parsons is clearly metaphorical. Even so, the sophistic application of the formula "All $S$ is $P$, by obversion, will be no $\mathrm{S}$ is non-P" by my dear critic is correct, and contrary to what he believes to have demonstrated, it contributes to the notion that health possesses a nature distinct from and irreducible to sickness.

Let us consider, following Castiel's line of argument, that $P=$ non(D), or absence of disease. Indeed, if $(S)=(P)$, it follows that

$(S)=\operatorname{non}(D)$,

by obversion,

non $(S)=\operatorname{non}[$ non(D)]

which, by reducing the negation of the nega-

tion, is equal to

non $(S)=(D)$,

thus

$(\mathrm{S}) \neq(\mathrm{D})$

It is thus valid to say, on the logical plane, that it is in fact a relationship of obversion, far from revealing its "fragility and impropriety". But after all, Castiel is free even to prescribe brief and gentle "puzzled pauses [to regulate our] irrepressible drive to know and produce objects". But as far as I am concerned, objects are precisely the noble product of this peculiar mode of production that constitutes science.

Cecília Minayo observes that "to date, health has never been treated as either a discipline or school of thought" but rather as a field of knowledge and practices, in the sense proposed by Bourdieu (1983). She thus considers it "quite problemati c to formulatea theory of health or health models" even though it may be possible "to theorize the health concept". In fact, my text was really not intended to enunciate but to announce a theory, covering some essential preliminary stages for the conceptual construction process. The first stage consisted of a duly justified proposition of the positivity of a given concept. I do not know if the text succeeded in meeting this prerequisite, but my explicit intent was to demonstrate the insufficiency of theoretical treatments of the health issue based on the notion of sickness or disease. The second stage aimed to refine the concept, making it more operational as a tool for systematizing thought on a complex object of knowledge. With regard to the present effort, I basically attempted to present and validate the following proposition: similar to the semantic variety of the disease-illness-sickness complex, we should construct an equivalent conceptual plurality, identifying various modes of health.

Minayo also suggests that I fell into a "theoretical trap" by identifying only the socio-anthropological and epistemological dimensions 
as structuring the health concept, leaving aside the biological dimension. In addition, she questions the very inclusion of the epistemological dimension at the same analytical level of the social sciences in health. Concerning the omission of the biological dimension, I believe that Minayo is right, but cross-sectional approaches impose necessary limits on analytical ambitions. In this sense, the most I can do is to promise to analyze the biological dimension subsequently, in light of the advances and debate produced by the text at hand. As to the question of whether the epistemological dimension is structuring or is part of the metaanalysis of theories, I would simply respond that this disjunction does not make sense. Epistemology may be structuring in an early stage of conceptual construction, resuming its metatheoretical or para-theoretical mandate as soon as the process of consolidating the object or field advances.

In the purposive part of her commentary, Minayo contributes with a proposal for differentiating heal th as a total social fact and as a concept handled by a specific field of practices and policies. She briefly analyzes the notion of health as a good, as a conquest, and as social expression, with references to Marcel Mauss's theory of the gift, as retrieved by French structuralism. She then launches into the confusion of logical types characterizing WHO's elaboration on the topic, quoting Oliver Sacks, who paraphrases Canguilhem, who studies Leriche, finally accepting a definition of health-disease anchored at the individual level. The proposal of various "healths", my modest contribution to the inauguration of this debate, unfortunately appears not to have been clear and thus requires ratification. According to my proposition, what Minayo calls health as a total social fact constitutes just one of the modes of health, provisionally designated as "social health" and which has its principal descriptor in the systems of signs, meanings, and practices. It is only as a localized indication that I believe health is theoretically less important as a "social fact" than as a "total fact".

Dina Czeresnia admits that "no scientific definition of health has been found to date," and that the link between the field of health and medicine makes it depend on a negativity to define its object. She thus agrees that it is important to attempt to move forward towards a theory of health destined to support risk prevention and health promotion practices (Czeresnia, 1999). Nevertheless, she suggests that it might be helpful to retrieve the ontological concept of sickness, reconsidering "theform in which this concept is organized in practices that either favor or jeopardizelife', which could function as a "margin and barrier" in the process of constituting the object of health (practice). She asks, "Without the inexorability of pain and suffering would a field of health make sense?" And she ends by identifying a possible contradiction between my transdisciplinary proposal/stance, organized as a problem or issue and not as a discipline, and the objective of constructing a General Theory of Health.

I agree that it would really not be possible to go too far in the proposed theoretical undertaking without decisively confronting the theoretical issue of sickness. It is not only the health concept that has been neglected. As I analyzed in my article, despite some well-meaning efforts, not enough progress has been made either for a satisfactory composition worthy of the name "general theory of sickness". However, I am convinced that it is an articulated project, but parallel to progress in the reflection on the concept of health, with distinct objectives and strategies. As for the second question, I see no contradiction between formulating a general (and not unified) theory of health and valuing alternative and plural modes of understanding the object. A general theory like the General Theory of Systems or the General The ory of Information will certainly have a sufficiently broad scope to incorporate restricted theories of health (or middle range theories, as suggested by Madel Luz) applied to each realm, plane of emergence, or facet in the health object-model.

In the reference to a general theory, as clearly understood by Suely Deslandes in her commentary, the health object may be in keeping with the articulations or interconnections between restricted theories as well as the effects of the horizontal invariance in the health models considered. In other words, "as many theories as there [are] alternative and plural modes of approaching this object" mentioned by Czeresnia doubtless need a meta-structure capable of integrating (and not unifying or merely homogenizing) the various object-models comprising the "single plurality" of health.

Taking another angle, Suely Deslandes picks up on the theme of the choice of functionalist authors as the target of criticism for the negative vision of health and demands that the analysis include "sociologists incorporated into the Collective Health debate (I i ke Habermas, Bourdieu, and Giddens)". Perhaps some important reference has escaped me, but as far as I know none of these authors has dealt directly with the issue of health or sickness. I am 
unaware of any theory of health in the Frankfurt school, in French post-structuralism, or in British post-Marxism. In the other watershed, as I analyzed in the text at hand, North American structural-functionalism chose the role of the sick individual as central to the social system theory, and interpretive medical anthropology proposed a partial theory of disease-illness-sickness.

Minayo also contends that my text "fails to escape this theoretical entanglement" (another way of indicating the purported theoretical trap) of Anglo-Saxon reductionist functionalism, claiming that the references on which I base my analysis forced a superficial and poorly systematized discussion of the theory of health. First, all the sociological and anthropological references were used in the article as the target of criticism and not for theoretical support. Second, the preliminary movement towards a theory of health could only conclude, and not precede, a guided process of conceptual deconstruction/construction.

Rita Barata also underscores this issue, but referring to other authors of a Marxist reference (Sigerist, Pollack, Garcia) who - and here I do indeed agree - produced theoretical contributions on health that could enrich the debate. Even so, and she herself agrees, none of them analyzed (or even intended to solve) the specific problem of a positive heal th concept or the absence-of-disease issue. The contribution by all these authors, defined by their critical stance towards the functionalist frame of reference, could not be useful for the project at hand simply because they do not serve as a target or contrast for the conceptual deconstruction I attempted to perform.

Barata further questions whether the analytical scheme developed by Bibeau \& Corin, despite being the only "truly social formulation among those analyzed by the author, recovering the historical, social, and collective dimensions of the health-disease process" is sufficient "to consider it an adequate descriptor for the category of social health proposed by the author". This is apparently a fair and timely critique, to the extent that the choice in fact implies an early closing of the proposed frame of reference. However, I should point out that all the indications in this conceptual trajectory are provisional, and this particular one even more so, given that it does not fit among the basic concepts of health disciplines, like risk, morbidity, measure, etc. As I observe later in the text, the reshaping of the SmpH theory by one of its authors in the face of critiques aimed at it in the context of the present debate indicates that this choice retains its heuristic value vis-àvis the theme of "social health".

Madel Luz provides an in-depth discussion of many of the points raised by the text at hand. She ascribes the theoretical vacuum in the health concept to "the predominance of the biomedical frame of referencein the social sciences", in culture, and in basic societal relations. I confess that it remained beyond the scope of my analysis to investigate the determinants of this conceptual blind spot in the social history of Western science, as Luz herself did (1989) in a pertinent and competent way. Referring to Foucault, she points to the institutional order of the biomedical and social disciplinary fields as a "set of identifications which 'expels' from its theoretical nucleus such positivities as health, life, or vitality". However, she recognizes that a positive conceptualization of health involves the epistemological and institutional deconstruction of the "medical order".

I am happy with the degree of understanding of my text's objectives as displayed by Luz, a partner in lengthy debates on the Collective Health object-model. As I said above, I am modestly happy with the claim to an epistemological deconstruction of an incipient conceptual order (the field of Collective Health), but I would not dare to expand the scope of the proposed critical interference to include an institutional order subject to such deeply established determinations. I agree both with her warnings concerning the danger of unified theories which historically take biomedicine as the basis for unification (note that my proposal is precisely the contrary) as well as with her recommendation to seek a general theory as a finishing line and not as a point of departure.

Jurandir Freire Costa raises the question of cognitive models and the necessary levels of abstraction to foster reflection on a GTH when he recommends "renouncing the intention to construct a meta-theory of health in favor of prompt descriptions, subject to revision and further in-depth development". As a collaboration to simplify research protocols, he proposes to divide the health field into two sets: that of physi calist descriptions - facts postulated as causally independent of meaning and that of mentalist descriptions - all of the mentally phenomenic "qualitative" aspects of the health experience. He ends by suggesting practical modes of implementing this strategy for the theoretical construction of the health object, referring to the difficulties in ensuring compatibility among disciplines and the levels of social validation needed for such a proposal. 
Such suggestions provide valuable contributions to the project, but I would like to discuss some specific points. First, to consolidate a meta-theory or general theory is not incompatible with developing restricted theories based on specific developments. As I have already discussed in responding to Deslandes and Minayo, and in total agreement with Luz, I believe it is desirable to conduct a parallel development of the general theory and the restricted theories of health-disease in order to mutually feed the processes of systematizing the cognitive models (or object-models, in Bungean terminology).

Second, as for the phenomenic sets proposed by Freire Costa, I believe that it is another issue of the level or plane of emergence, in which one should also consider mixed descriptions (physicalist and mentalist, parallel or convergent - hence the risk concept is certainly the best example). Finally, I agree with the limited feasibility of obliging "specialists" to command distinct areas of knowledge, given that encyclopedism as a project has long since vanished. However, as I indicated in another series of articles (Almeida Filho, 1997, 1998, 2000), a pragmatic proposal for transdisciplinarity can deal with the necessary synthesis of health as an object-model, single and plural, by means of a new encyclopedism based on the circulation of subjects and not the transfer of disciplinary discourses. In my opinion the conclusion to the commentary by Freire Costa is perfect: we must respect the language of the paradigms without confusing incommensurability with untranslatability.

Jaime Breilh consi ders the discussion of a General Theory of Health timely, precisely at this moment in which what are called "general scientific frameworks" are being questioned. I thank him for his series of positive comments on my proposition and move on immediately to deal with the critical points he identified. First, Breilh criticizes the excessive dependency on the text's line of argument in relation to European thought and its successors. He is right on this point. Of course the important contribution by the Argentine philosopher Juan Samaja alone could not counterbalance the conceptual construction on the theme of sickness performed by the social sciences applied to health in the Anglo-Saxon context or the French epistemological tradition. The work of Breilh himself $(1990,1995)$, and that of Pedro Luiz Castellanos (1997), Luiz David Castiel (1994), José Ricardo Ayres (1997), Dina Czeresnia (1999), and many others have certainly contributed greatly to the robustness of the ar- gument. What I can say is that I consider them a "theoretical reserve" for subsequent stages in the conceptual construction process that awaits us.

Second, Breilh introduces a subtle critique towards the academicism and elitism of my arguments, highlighting that the construction of a scientific discourse on health is too serious a matter to be left exclusively to scientists. He contends that a General Theory of Health "should encompass the historical subjects mobilized around the object as a field of action", but he does not identify such a possibility in my proposition. He recommends that the necessary theoretical construction be conducted based on the dissolution of separations between "subject", "objective world", and "mass" imposed by positivist rationalism. In short, he proposes to radical ly politicize any attempt at developing theories of health, whether general or restricted, employing a reference from multiculturalism that shifts from the original anthropological extraction to a voluntarist militant version.

In this regard, Breilh and I harbor a radical disagreement: while he believes that the persons who are the object of research are subjects fully capable of directly grasping the process of producing knowledge on their own lives, contexts, and systems of thought, I contend that research is a professional practice exercised by those who undergo structured processes of theoretical and methodological training. The concrete subjects constitute subjects of their own lives and health, I agree, but the agents who produce research are subjects of a peculiar institutional and ideological order which, whether we like it or not, achieves relative social and political autonomy in Western social formations. As acknowledged by Bibeau (see below), the notion of social health and the reference to $\mathrm{SmpH}$ implies a conscious and feasible opening towards social discourses on health and its correlates, mediated by research praxis.

Gilles Bibeau, one of the authors of the the ory of "systems of si gns, meanings, and practices in health", recognizes that few anthropologists have taken interest in developing an anthropology of health as opposed to the perspective of disease prevailing in this field. By positioning himself vis-à-vis the nature of popular semeiologies as the basis of belief systems and the role of science as a social and historical response to human demands (including demands for health), he takes a stance that surmounts the romantic ethnoscience movement in vogue in the 1960s. He uses these foundations to "enthusiastically" support both the 
General Theory of Health project and the deconstructionist and integralizing strategy pursued in the text at hand. He presents a robust line of argument supporting what he considers convergence in our reflection: the search for positivity in the concept, anchored in the discourse of science, in parallel with the introduction of what he calls "local epistemologies" in the construction of a General Theory of Health.

Bibeau effectively "buys" the ideas of conceptual plurality and transdisciplinarity, aligning strategic themes to support the proposal under debate. He begins by discussing the "quest for perfect health" and the "well-being complex" as structuring symbolic sets in the dominant ideology in post-industrial capitalist countries, in which notions like promotion and prevention provide the basis for technological undertakings in social intervention. Next, he approaches the contemporary trend to consider the historicity and relativity of biology, suggesting that perspectives be opened for a new and solid integration between socio-cultural and biodynamic health paradigms. He enriches the line of argument proposed in my text by introducing the linguistic issue as the basis for symbolic and phenomenological analysis of the health-disease complex and its effects and correlations. He then reaffirms the position of considering interconnections between collective systems of meaning, local health idioms, and individual discourses of well-being as essential to articulate a theoretical model of health which in fact respects the complexity of the corresponding phenomenic processes. Evaluating this section of his commentary, I note with great satisfaction that Bibeau intends to move forward with the theory of "systems of signs, meanings, and practices in health", absorbing and incorporating the critique that this theory remained committed to illness models.
In the second part of his commentary, Bibeau aims to contribute to the strategic part of the process of theoretical construction, emphasizing the value of "local epistemologies" for integralizing the heal th object. He initially justifies this perspective based on the notion of cultural complexity (Hannerz, 1993), pointing out its dialectic nature as a concept based on contradictory pairslikelocal-global, center-periphery, inclusion-exclusion, and majority-minority. As both a challenge and a promising way out, he comprehends the processes of "creolization" of societies and their cultural systems. He then takes advantage of the opportunity of this debate to indicate that, given that science also constitutes an ideological and institutional network that is part of the modern West's cultural system, it is licit to consider the possibility of a "creolized science".

In the case of the health sciences and their hybrid, plural, and imprecise objects, Bibeau unveils the important role of local epistemologies, which found "popular diseases" and "semantic health networks" on the basis of "implicit health theories". The expl oration of such elements by means of competent ethnographic approaches, conscious of their limits as "local knowledge" (Geertz, 2000), constitutes a requisite for grasping the "systems of signs, meanings, and practices in health" which, with greater propriety after this, is justified as a descriptor of "social health" or "health imaginary". In this sense, Bibeau concludes with a quote by North American researcher Victor Turner, who launched an important line of anthropological investigation of suffering, highlighting an expression which in my view will constitute a basic notion for future ethnografies of "social health", becoming a key concept for any creole grammar of the health-disease complex: "the good life". But this is the subject for a new debate... 


\section{References}

ALMEIDA FILHO, N., 1992. A Clínica e a Epidemiologia. Salvador: APCE/Rio de Janeiro: ABRASCO.

ALMEIDA FILHO, N., 1997. Transdisciplinaridade e saúde coletiva. Ciência \& SaúdeColetiva, 2:5-20.

ALM EIDA FILHO, N., 1998. Sobre as relações entre complexi dade e transdisciplinaridade em saúde. Revista da ABEM, 22:22-30.

ALMEIDA FILHO, N., 2000. Intersetorialidade e transdisciplinaridade em saúde. Revista Brasileira de Administração Pública, 34:11-34.

AYRES, J. R., 1997. Sobre o Risco - Para Compreender a Epidemiologia. São Paulo: Editora Hucitec.

BECK, U., 1996. La sociedad del riesgo. In: Las Concecuencias Perversas de la Modernidad: Modernidad, Contingencia y Riesgo (J. Beriain, org.), pp. 182-201, Barcelona: Anthropos.

BOORSE, C., 1977. Health as a theoretical concept. Philosophy of Science, 44:542-573.

BOURDIEU, P., 1983. O campo científico. In: Pierre Bourdieu:Sociologia (R. Ortiz, org.), pp. 122-155, São Paulo: Editora Ática.

BREILH, J., 1995. Epidemiology's role in the creation of a humane world: Convergences and divergences among the schools. Social Science and Medicine, 41:911-914.

BREILH, J., 1990. Reprodução social e investigação em saúde coletiva. Construção do pensamento e debate. In: Epidemiologia, Teoria eObjeto (D. C. Costa, org.), pp. 137-165, São Paulo: Editora Hucitec/ ABRASCO.

CASTELLANOS, P., 1997. Epidemiologia, salud publica, situación de salud y condiciones de vida. In: Condiçoes deVida eSituação de Saúde (R. Barata, org.), pp. 24-32, Rio de Janeiro: Editora Fiocruz/ ABRASCO.
CASTIEL, L. D., 1994. O Buraco e o Avestruz - A SinguIaridadedo Adoecer Humano. Campinas: Papirus. COSTA-CAPRA, R., 1995. Fuzzy logic and epidemiologic reasoning. In: II Congresso Ibero-Americano de Epidemiologia, III Congresso Brasileiro de Epidemiologia, Resumos, p. 305. Salvador: ABRASCO.

CZERESNIA, D., 1999. The concept of health and the difference between prevention and promotion. Cadernos de Saúde Pública, 15:701-709.

GADAMER, H.-G., 1996. The Enigma of Health. Berkeley: Stanford University Press.

GEERTZ, C., 2000. "Local knowledge" and its limits. In: Available Light: Anthropological Reflections on Philosophical Topics (C. Geertz, ed.), pp. 133-142, Princeton: Princeton University Press.

GIDDENS, A., 1990. The Consequences of Modernity. Cambridge: Polity Press.

HANNERZ, U., 1993. Cultural Complexity: Studiesin the Social Organization of Meaning. New York: Columbia University Press.

LAKOFF, G., 1993. Women, Fire and Dangerous Things. Berkeley: University of California Press.

LUZ, M., 1989. Natural,Racional,Social. Rio de Janeiro: Graal.

MEZZICH, J. \& ALMEIDA FILHO, N., 1994. Epidemiology and diagnostic systems in psychiatry. Acta Psychiatrica Scandinavica, 90(Sup. 385):61-65.

MIETTINEN, O., 1985. Theoretical Epidemiology. New York: John Wiley $\&$ Sons.

PARSONS, T., 1978. Action Theory and Human Condition. New York: Free Press.

SADEGH-ZADEH, K., 2000. Fuzzy health, illness, and disease. Journal of Medicine \& Philosophy, 25: 605-638.

SAM AJA, J., 1994. Epistemologia y Metodología. Buenos Aires: EUDEBA.

SAMAJA, J., 2000. A Reprodução Social ea Saúde Salvador: Casa da Saúde. 